Article

\title{
Adaptive Sliding Mode Control for a Double Fed Induction Generator Used in an Oscillating Water Column System
}

\author{
Oscar Barambones * $\mathbb{D}$, Jose M. Gonzalez de Durana and Isidro Calvo \\ Faculty of Engineering of Vitoria-Gasteiz, University of the Basque Country (UPV/EHU), Nieves Cano 12, \\ 01006 Vitoria-Gasteiz, Spain; josemaria.gonzalezdedurana@ehu.eus (J.M.G.d.D.); isidro.calvo@ehu.eus (I.C.) \\ * Correspondence: oscar.barambones@ehu.es; Tel.: +34-945-013-235; Fax: +34-945-013-270
}

Received: 23 September 2018; Accepted: 25 October 2018; Published: 27 October 2018

\begin{abstract}
Wave power conversion systems are nonlinear dynamical systems that must endure strong uncertainties. Efficiency is a key issue for these systems, and the application of robust control algorithms can improve it considerably. Wave power generation plants are typically built using variable speed generators, such as the doubly fed induction generator (DFIG). These generators, compared with fixed speed generators, are very versatile since the turbine speed may be adjusted to improve the efficiency of the whole system. Nevertheless, a suitable speed controller is required for these systems, which must be able to avoid the stalling phenomenon and track the optimal reference for the turbine. This paper proposes a sliding mode control scheme aimed at oscillating water column (OWC) generation plants using Wells turbines and DFIGs. The contributions of the paper are (1) an adaptive sliding mode control scheme that does not require calculating the bounds of the system uncertainties, (2) a Lyapunov analysis of stability for the control algorithm against system uncertainties and disturbances, and (3) a validation of the proposed control scheme through several simulation examples with the Matlab/Simulink suite. The performance results, obtained by means of simulations, for a wave power generation plant (1) evidence that this control scheme improves the power generation of the system and (2) prove that this control scheme is robust in the presence of disturbances.
\end{abstract}

Keywords: renewable energy; wave energy; adaptive SMC; DFIG; lyapunov methods

\section{Introduction}

During the last decade, the use of renewable energy sources (mainly wind and solar) have gained increasing attention for several reasons such as the reduction of pollution caused by traditional sources of energy (mainly fossil fuels) and the removal of dependence on exhausted resources. Nowadays, the scientific community is focusing on wave energy due to its potential for supplying a considerable part of the electricity demand in some countries [1-5].

The wind over the ocean surface is a major cause of the waves. In many areas of the world, the wind generates continuous waves that may be converted into power in a consistent way. Following diverse approaches, several devices are being designed to harness the massive energy of the waves, either by extracting energy from the waves motion over the ocean surface or by benefiting from the pressure fluctuations below the surface [6-8]. In this work, a Wells turbine-based oscillating water column (OWC) device is used for converting the energy of the waves into mechanical energy [9]. The obtained mechanical energy depends on the wave characteristics-mainly height, speed, wavelength, and water density [10,11].

The doubly fed induction generator (DFIG) is used at many renewable power generation plants (e.g., wind turbines and wave energy plants) since they are able to adapt to sudden changes [12-16]. 
In these machines, the stator is connected directly to the grid, but the rotor is connected to the grid by means of a variable frequency converter (VFC). This configuration benefits from the fact that the VFC only manages a fraction, around (25-30\%), of the nominal power for controlling the generator. Typically, one voltage source of the VFC is located at the grid side, the so-called grid-side converter (GSC), another is located at the rotor side, the so-called rotor-side converter (RSC), and a capacitor is used to connect back to back both converters [17-19].

The most frequent strategy to control these systems is a combination of vector control with cascaded PI control for current and power [20]. However, the nonlinear nature of these systems and their uncertainties suggest that the use of a more robust controller could improve the system performance.

One alternative is considering the sliding mode control (SMC) technique. SMC has proven to be suitable at systems in which a precise model is known. In addition, it reduces the sensitivity to variation parameters and rejects external disturbances [21,22]. During the last decade, the SMC techniques have been applied to control several types of electrical devices obtaining good results [23-26].

Traditionally, in OWC systems, the rotational speed of the turbine is adjusted taking into account the maximum pneumatic energy level available to the turbine [27-29]. However, in the control scheme proposed in this work, a new reference for the turbine speed, based on the airflow velocity, is proposed.

This work presents an SMC scheme aimed at improving the generation of power in an OWC system that incorporates a Wells turbine in order to transform the pneumatic energy into mechanical energy. The proposed approach is aimed at tracking the speed of the turbine in order to maximize power extraction. SMC theory and DFIG rotor current regulation were used to control the turbine speed. By regulating the speed of the turbine, the flow coefficients are optimized in order to maximize power generation even when there are uncertainties in the model or variations in the wave power.

The design of the traditional SMC scheme requires calculating an upper bound for the system uncertainties since the value of the sliding gain used must be higher. This value is directly related to the control effort, so a high sliding gain value implies a high control effort possibly causing the chattering problem. This problem arises because the sliding control signal is discontinuous across the sliding surfaces, so this kind of signal involves high control activity and may also excite the high frequency dynamic of the system. Therefore, the system uncertainties should be bounded accurately. In order to avoid this problem, the proposed control scheme includes an adaptive law to calculate the sliding gain.

The closed loop stability of the proposed control scheme was proven using the Lyapunov stability theory. The performance of this control scheme is validated by means of the Matlab/Simulink software. The conditions of operation, as well as the simulation results, are discussed in detail.

This paper is organized as follows: Section 2 presents a model for the plant used, the OWC. Section 3 introduces the design of the adaptive sliding mode control scheme. Section 4 presents the simulation results obtained. Section 5 presents the conclusions.

\section{OWC Plant Model}

In this work, an OWC system with a Wells turbine and a DFIG is considered.

Figure 1 shows how the OWC device uses the hydraulic energy of the waves to create an oscillating air flow that moves the turbine.

In an OWC system, the chamber collects the flow of air generated by the ocean waves. At the top of this chamber, there is a turbine, which is connected to a generator by means of a gear box. The airflow in the chamber is bidirectional since it depends on whether the waves hit or reflect. However, the Wells turbine rotates always in one direction, independently of the air flow direction, which has proven very useful to be used in maritime energy. This turbine was designed by Prof. Alan Arthur Wells of Queen's University Belfast at the end of the 1970s. 
The power that can be extracted from the airflow in the chamber of the OWC is determined by [30]

$$
P_{i n}=\left(d P+\frac{\rho v_{x}^{2}}{2}\right) v_{x} a
$$

where $v_{x}(\mathrm{~m} / \mathrm{s})$ is the speed of the airflow, $d P(P a)$ is the pressure drop at the turbine, and $a\left(m^{2}\right)$ is the area of the turbine duct.

It should be noted that the equations for the OWC system are quite similar to the equations obtained for the wind turbine systems. The term $\rho v_{x}^{3} a / 2$, that also appears in the wind turbines, takes into account the kinetic energy. The other term $d P v_{x} a$ takes into account the air pressure in the chamber and appears owing to an OWC chamber.

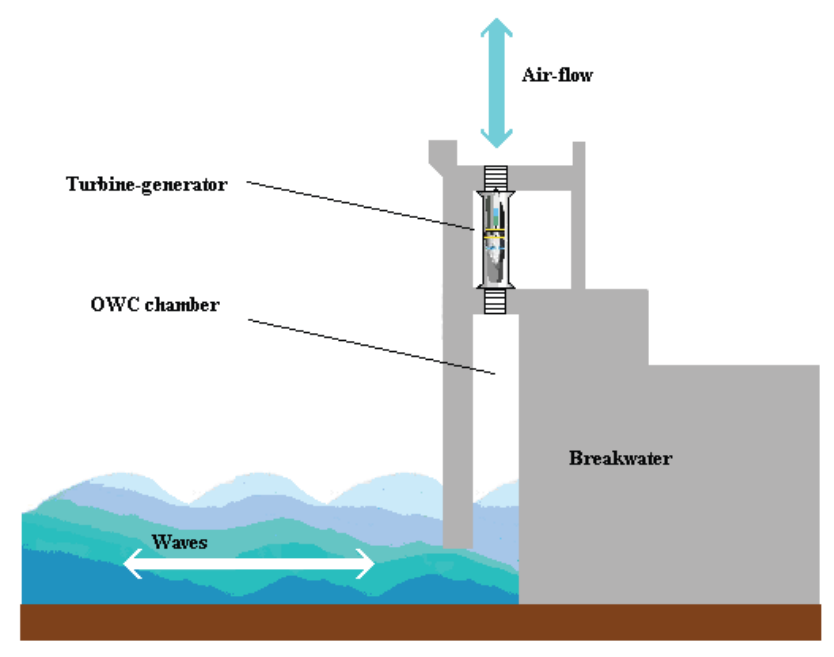

Figure 1. The oscillating water column (OWC) wave power system.

In this work, the turbogenerator module of the OWC is used with a Wells turbine, which is connected to a DFIG by means of a gearbox.

The DFIG is an induction machine typically used in renewable electric generation devices, such as wind turbines. A VFC is used to connect the rotor circuit of the DFIG to the grid, whereas the stator is directly connected. In order to deliver active power to the grid, regarding the frequency and voltage stability requirements of the grid, the flow between rotor and grid must be controlled in magnitude and direction. However, these machines are designed to operate at an extended range of rotational conditions, from subsynchronous to supersynchronous speed.

The use of this configuration allows that the power electronic converters deliver electrical power to the grid by managing a fraction of the nominal power, typically between 25 and $30 \%$. The power generated at the stator goes directly to the grid, whereas the power obtained at the rotor is delivered by means of a VFC. As a result, the power converters needed can be relatively smaller when compared with other configurations. Moreover, this configuration provides additional benefits, such as improving the performance and reducing the cost of the equipment.

Typically, at this type of systems an inertia wheel drive is included for smoothing the curve of the output power delivered by the generator. This component facilitates the application of SMC schemes at these systems, since some phenomena that may appear, such as the chattering problem, can be absorbed by the inertia wheel.

This work assumes the use of Wells turbines for extracting the energy of the airflow. These turbines are designed to always turn in the same direction, independently of the sense of the airflow that moves the turbine, providing a robust behavior. The key at these turbines is the design of the 
blade, which is simple and symmetrical. The mathematical model for these turbines is given by the following equations [31]:

$$
\begin{aligned}
d P & =C_{a} k_{t} \frac{1}{a}\left[v_{x}^{2}+(r w)^{2}\right] \\
T_{t} & =C_{t} k_{t} r\left[v_{x}^{2}+(r w)^{2}\right] \\
T_{t} & =\frac{C_{t} r a}{C_{a}} d P \\
k_{t} & =\rho b n \frac{l}{2} \\
\phi & =\frac{v_{x}}{r w} \\
q & =v_{x} a \\
\eta & =\frac{T_{t} w}{q d P}
\end{aligned}
$$

where $T_{t}(\mathrm{Nm})$ is the generated torque at the Wells turbine, $\phi$ is the flow coefficient, $C_{a}$ is the power coefficient, $C_{t}$ is the torque coefficient, $k_{t}(\mathrm{Kg} \cdot \mathrm{m})$ is a turbine specific constant, $r(m)$ is the radius or the turbine, $v_{x}(\mathrm{~m} / \mathrm{s})$ is the speed of the airflow, $w(\mathrm{rad} / \mathrm{s})$ is the rotational speed of the turbine, $b(\mathrm{~m})$ and $l(m)$ are constants related to the blades - respectively, the blade height and the blade chord length $-n$ is the number of blades, $q\left(\mathrm{~m}^{3} / \mathrm{s}\right)$ is the flow rate, $a\left(\mathrm{~m}^{2}\right)$ is the cross-sectional area of the turbine, and $\eta$ is the efficiency of the turbine.

According to the equations of the presented model, both the torque and power generated by a Wells turbine can be obtained from the torque and power coefficients, respectively. The characteristic curves of the Wells turbine show the relationship between the torque and power coefficients versus the flow coefficient.

The performance of a Wells turbine decreases severely when the speed of the airflow goes beyond a critical value, which depends on the rotational speed of the turbine [31]. This phenomenon is known as stalling, since the Wells turbine stalls when the relative angle formed by the axial speed of the input airflow and the tangential velocity of the turbine surpasses a specific value. This value is typically close to $14^{\circ}$.

Figure 2 depicts the torque versus flow coefficients $\left(\phi=\frac{v_{x}}{r w}\right)$ for a specific Wells turbine. It can be seen in the figure that the value of $C_{t}$, the torque coefficient of the turbine, decreases severely when the turbine stalls (due to the stalling phenomenon). Even though this figure was obtained for a specific turbine and in general the behavior depends on some constructive parameters, the characteristic curves for diverse turbines present similar features.

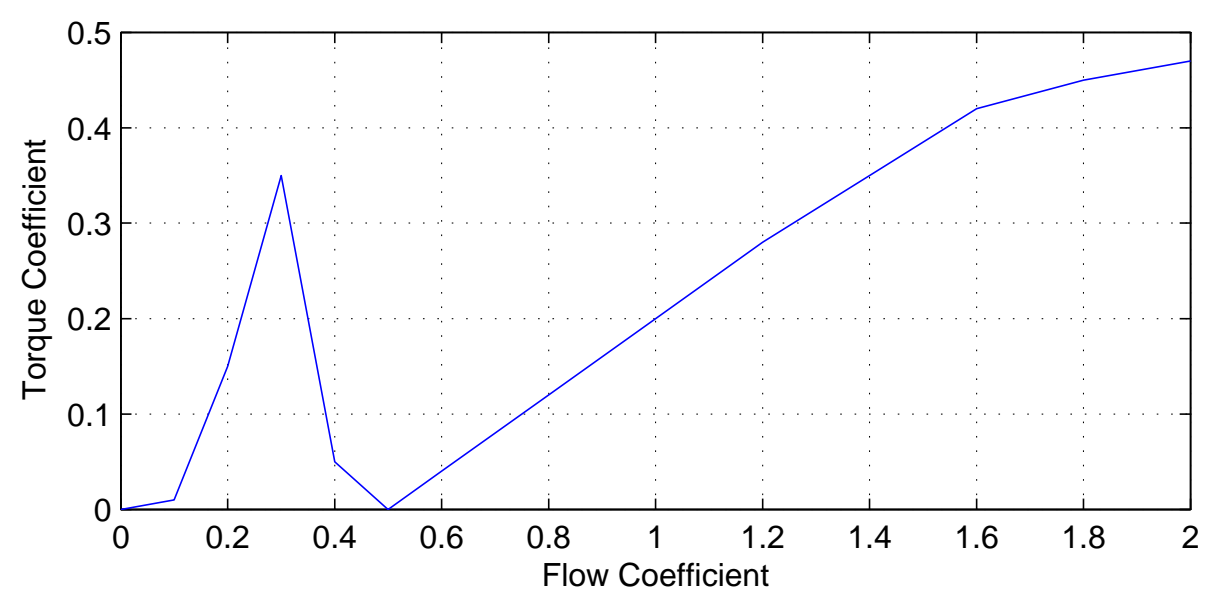

Figure 2. Torque coefficient versus flow coefficient. 
For this specific turbine, Figure 2 illustrates that, when the flow coefficient reaches the value of $\phi=0.3$, stalling occurs. As remarked above, the value for the flow coefficient differs depending on the characteristic curve for a specific Wells turbine. It may be concluded from the picture that a value for the flow coefficient of around $\phi_{o p t}=0.29$ is a good alternative. On one side, this value avoids the phenomenon of stalling and maximizes the value for torque $C_{t}$.

Since the movement of the airflow is caused by the ocean waves, which have an oscillatory nature, the value of the flow coefficient is consequently oscillating between zero and a positive value. Thus, the optimal zone of operation for the turbine is located from zero to the point at which the stalling phenomenon appears.

Taking into account the previous considerations and using Equation (6), the reference value for the turbine speed that maximizes the power extraction from the ocean waves can be obtained from

$$
w^{*}=\frac{v_{x}}{r \cdot \phi_{o p t}} .
$$

Therefore, the flux coefficient in the Wells turbine may be optimized using an adequate turbine speed regulation that follows the reference value given by Equation (9).

\section{Adaptive Sliding Mode Control Scheme for an OWC}

In a DFIG-based OWC wave energy converter, the extracted power may be maximized by regulating the rotational speed of the Wells turbine. Thus, the value for the flux coefficient can be optimized while avoiding the stalling phenomenon. This objective may be achieved by means of an adaptive SMC scheme that controls the rotational velocity at the DFIG, which may be achieved using the quadrature component of the current at the rotor.

In the discussion about the model of the OWC system, it was pointed out that the shaft speed for the turbogenerator should be adjusted below the stalling phenomenon. Thus, the flow coefficient $\phi$ value provides an optimum value that extracts the maximum power from the sea waves. This would produce the maximum value for the torque coefficient $C_{t}$ while avoiding stalling.

For a given pressure drop input $d P$, there is only a unique value for the speed reference that satisfies the condition for finding the optimum flow coefficient that maximizes the extraction of energy from the waves. This value can be obtained from the characteristic curve supplied by the manufacturer of the turbine. Obviously, this procedure is valid for any Wells turbine since they always present a similar stalling phenomenon.

This approach for designing the control scheme is quite similar to other well-established DFIG-based applications. The control strategies aimed at extracting the maximum power in wind turbines follow a similar approach. In such applications, the controller should follow the tracking reference in order to control the speed of the turbine. The tracking reference depends on the maximum variation of the power with the angular velocity for the DFIG. Obviously, the reference should differ since the aerodynamic characteristics for every turbine are also different, provided that different characteristic curves form the power coefficient versus the tip speed ratio [32].

The design of the adaptive SMC is based on the dynamics of the turbogenerator. Consequently, a dynamic model for the turbogenerator must be obtained. The dynamics of the turbogenerator involves both mechanical and electrical areas.

The following equation models the dynamics for the mechanical part of the turbogenerator:

$$
J \mathfrak{w}+B w=T_{t}-\gamma T_{e}
$$

where $T_{t}$ is the turbine torque, generated by the airflow induced by the waves, $B$ is the viscosity coefficient, $T_{e}$ is the torque generated by the generator, $J$ is the moment of inertia, $w$ is the rotational velocity for the turbine, and the gear ratio $\gamma=w_{e} / w$ yields the ratio between the rotational speeds for the turbine, $w$, and the generator rotor, $w_{e}$. 
The use of vector control techniques simplifies the DFIG model, since all expressions are referred to the stator flux reference frame. The d-axis is aligned with the stator flux linkage vector $\psi_{s}$; thus, $\psi_{d s}$ $=\psi_{s}$ and $\psi_{q s}=0$. The following expressions are thus obtained [33]:

$$
\begin{aligned}
i_{q s} & =-\frac{L_{m} i_{q r}}{L_{s}} \\
i_{d s} & =\frac{L_{m}\left(i_{m s}-i_{d r}\right)}{L_{s}} \\
i_{m s} & =\frac{v_{q s}-r_{s} i_{q s}}{w_{s} L_{m}} \\
T_{e} & =-\frac{3 p}{4} \frac{L_{m}^{2} i_{m s} i_{q r}}{L_{s}} \\
v_{q r} & =r_{r} i_{q r}+\sigma L_{r} \frac{d i_{q r}}{d t}+s w_{s}\left(\sigma L_{r} i_{d r}+\frac{L_{m}^{2} i_{m s}}{L_{s}}\right) \\
v_{d r} & =r_{r} i_{d r}+\sigma L_{r} \frac{d i_{q r}}{d t}-s w_{s} \sigma L_{r} i_{q r}
\end{aligned}
$$

where $i_{q s}$ and $i_{d s}$ are the q-d components for the current at the stator, $i_{q r}$ and $i_{d r}$ are the $q-d$ components for the current at the rotor, $L_{s}, L_{r}$, and $L_{m}$ are the stator inductance, rotor inductance, and mutual inductances, respectively, $i_{m s}$ is the current for magnetizing the stator, $w_{s}$ is the angular velocity of the synchronous reference, $s w_{s}=w_{s}-w_{e}$ is the slip frequency, $w_{e}$ is the velocity for the rotor at the generator, $v_{q r}$ and $v_{d r}$ are the $\mathrm{q}-\mathrm{d}$ components of the voltage at the rotor, $\sigma=1-\frac{L_{m}^{2}}{L_{s} L_{r}}$ and $p$ is the pole numbers.

The current for magnetizing the stator $\left(i_{m s}\right)$ may be taken as a constant value due to that the stator resistance has small influence and the stator is directly connected to the grid [17]. Accordingly, the electromagnetic torque can be calculated as follows:

$$
T_{e}=-K_{T} i_{q r}
$$

where the torque constant value $K_{T}$ is calculated below:

$$
K_{T}=\frac{3 p}{4} \frac{L_{m}^{2} i_{m s}}{L_{s}} .
$$

Substituting Equation (17) into Equation (10), a new expression for the dynamics is obtained. This expression includes the uncertainty terms:

$$
\dot{w}=-\left(c_{1}+\triangle c_{1}\right) w+(f+\triangle f)-\left(c_{2}+\triangle c_{2}\right) i_{q s}
$$

where $c_{1}=\frac{B}{T}, c_{2}=\frac{\gamma K_{T}}{J}, f=\frac{T_{t}}{T}$, and the terms $\Delta c_{1}, \Delta c_{2}$, and $\triangle f$ represent the uncertainties of the terms $c_{1}, c_{2}$, and $f$, respectively.

The dynamic Equation (19) can then be rewritten as

$$
\dot{w}=-c_{1} w+f+-c_{2} i_{q s}+\Delta(t)
$$

where all terms related to the uncertainty have been represented as $\Delta$ :

$$
\Delta(t)=-\triangle c_{1} w(t)+\triangle f(t)-\triangle c_{2} i_{q r}(t) .
$$

Considering the properties of the SMC scheme, the proposed adaptive sliding mode compensates the uncertainties of the system. 
The tracking error for the rotational velocity is defined with the following expression:

$$
e(t)=w(t)-w^{*}(t)
$$

where $w^{*}$ is the reference for the turbine speed that maximizes power extraction from ocean waves.

The time derivative of the previous expression is

$$
\dot{e}(t)=\dot{w}-\dot{w}^{*}=-c_{1} w(t)+f(t)-c_{2} i_{q r}(t)-\dot{w}^{*}(t)+\Delta(t) .
$$

An adaptive SMC scheme aimed at tracking the reference for the turbine velocity is then proposed. This controller is able to extract the maximum power from the waves in spite of the uncertainties at the plant.

The sliding variable $S(t)$ may be set as

$$
S(t)=e(t)+\int_{0}^{t} k e(\tau) d \tau
$$

where $k$ represents a positive constant value for the gain.

The sliding surface proposed is as follows:

$$
S(t)=e(t)+\int_{0}^{t} k e(\tau) d \tau=0
$$

As a consequence, the sliding mode controller for the velocity is obtained:

$$
i_{q r}^{*}(t)=\frac{1}{c_{2}}\left[k e+\hat{\beta} \gamma \operatorname{sgn}(S)-c_{1} w-w^{*}+f\right]
$$

where $\hat{\beta}$ is the estimated switching gain, $k$ is the gain defined previously, $S$ is the sliding variable defined in Equation (24), $\operatorname{sgn}(\cdot)$ is the signum function, and $\gamma$ is a positive constant.

It should be noted that the control Equation (26) includes some terms that compensate the known dynamics of the system $\left(c_{1} w-w^{*}+f\right)$ and other terms that compensate the uncertainties $(k e+\hat{\beta} \gamma \operatorname{sgn}(S))$.

The updating law for the switching gain $\hat{\beta}$ is defined as

$$
\dot{\hat{\beta}}(t)=\gamma|S(t)| \quad \hat{\beta}(0)=0
$$

where the adaptation speed for the switching gain can be selected using the positive parameter $\gamma$.

The following condition should be fulfilled to obtain the tracking signal for the speed reference:

$(\mathcal{C} 1)$ There are a finite and positive switching gain, $\beta$, which verifies the following:

$$
\beta>\Delta_{\max }
$$

where $\Delta_{\max } \geq|\Delta(t)| \quad \forall t$.

Note that further knowledge is not required for the upper bounds for the uncertainties. This assumption implies that the system uncertainties are bounded.

The Lyapunov stability theory will be used for ensuring the closed loop stability of the proposed control scheme for the wave power plant that moves the DFIG. This scheme implements the control law of Equation (26) using the value of Equation (27) for obtaining the switching gain. The dynamics for the DFIG is provided by (19).

Proof. The Lyapunov function candidate may be declared as 


$$
V(t)=\frac{1}{2} S(t) S(t)+\frac{1}{2} \tilde{\beta}(t) \tilde{\beta}(t)
$$

where $\tilde{\beta}(t)=\hat{\beta}(t)-\beta$ and $S(t)$ is the previously defined sliding variable.

The time derivative of the previous Lyapunov function candidate is

$$
\begin{aligned}
\dot{V}(t)= & S(t) \dot{S}(t)+\tilde{\beta}(t) \dot{\tilde{\beta}}(t) \\
= & S \cdot[\dot{e}+k e]+\tilde{\beta}(t) \dot{\hat{\beta}}(t) \\
= & S \cdot\left[-c_{1} w+f-c_{2} i_{q r}-\dot{w}^{*}+\Delta+k e\right]+\tilde{\beta} \gamma|S| \\
= & S \cdot\left[-c_{1} w+f-\left(k e+\hat{\beta} \gamma \operatorname{sgn}(S)-c_{1} w-\dot{w}^{*}+f\right)-\dot{w}^{*}+\Delta+k e\right] \\
& \quad+(\hat{\beta}-\beta) \gamma|S| \\
= & S \cdot[\Delta-\hat{\beta} \gamma \operatorname{sgn}(S)]+\hat{\beta} \gamma|S|-\beta \gamma|S| \\
= & \Delta S-\hat{\beta} \gamma|S|+\hat{\beta} \gamma|S|-\beta \gamma|S| \\
\leq & |\Delta||S|-\beta \gamma|S| \\
\leq & |\Delta||S|-\Delta_{\max } \gamma|S| \\
\leq & 0 .
\end{aligned}
$$

It should be indicated that in this proof the condition $(\mathcal{C} 1)$ and the Equations (23), (24), (26), and (27) have been used.

Based on the previous results, it can be stated that $\dot{V}(t)$ is a negative definite function. Hence, $V(t)$ is a positive definite function, and, when $S(t)$ tends to infinity, $V(t)$ tends to infinity. Consequently, it can be concluded that the equilibrium at the origin $S(t)=0$ is globally asymptotically stable by means of the stability theory of Lyapunov. Accordingly, when time tends to infinity, $S(t)$ goes to zero. This means that the trajectories that start out of the sliding surface will reach it and must remain in this sliding surface. This behavior is commonly called sliding mode [34].

When the sliding surface, Equation (25), is reached, both $S(t)$ and $\dot{S}(t)$ decrease to zero. At that time, the dynamic behavior of this system tracking problem can be represented by the following equation:

$$
\dot{S}(t)=0 \quad \Rightarrow \quad \dot{e}(t)=-k e(t) .
$$

Considering that $k$ is a positive constant it can be concluded that $e(t)$ converges exponentially to zero.

Therefore, the presented sliding mode control scheme can be employed in order to regulate the speed of the Wells turbine for wave power generation plants. This control scheme has been designed in order to extract the maximum power from the ocean waves under some uncertainties in the parameters of the system and under unmodeled dynamics.

\section{Simulation Results}

In this section, the performance of the proposed adaptive SMC scheme designed to regulate the turbine speed in an OWC wave power generator system is analyzed by means of some simulation examples. The goal of this control scheme is to obtain the maximum electrical power using the mechanical power extracted from the waves. For that, the optimal turbine speed command (that yields the maximum mechanical power) should be tracked by the turbine speed. In the following simulations, the proposed optimum tracking control scheme (that tracks the oscillating dynamics of the air flow in order to optimize the flow coefficient value) is compared with a control scheme without this optimum tracking control (the controller does not track the air flow variations in order to optimize the flow coefficient value). 
Figure 3 shows the block diagram of the proposed adaptive SMC scheme designed to regulate the speed of the turbine. In this figure, the block "Reference Generator" gives the reference for the turbine speed in order to obtain the optimum flow coefficient and accordingly the maximum power. This block is implemented by Equation (9). The block "SMC" is the proposed adaptive SMC that provides the rotor current control designed to track the reference speed. This block is implemented by Equation (26).

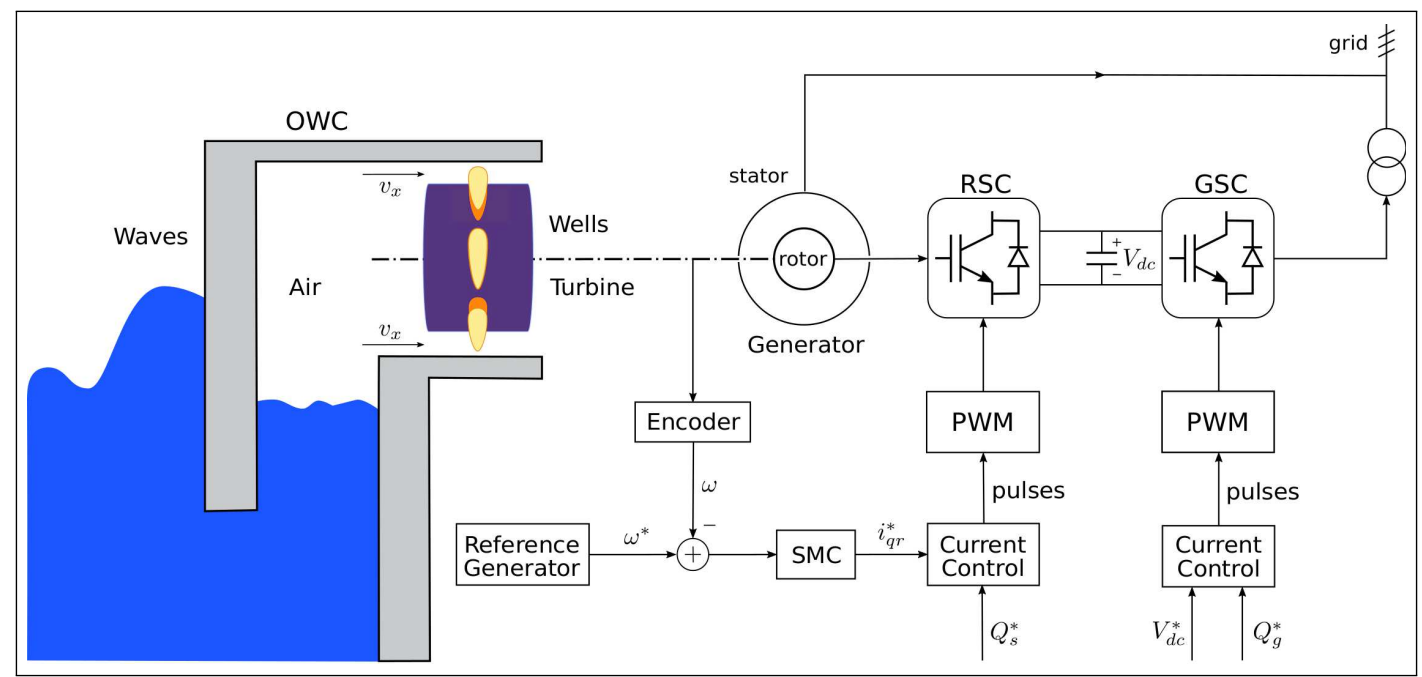

Figure 3. Block diagram of the proposed sliding mode control (SMC) scheme.

The Wells turbine used in the simulations has the following parameters:

- $n=5$ (number of blades);

- $k=0.7079 \mathrm{Kg} \mathrm{m}$ (turbine torque coefficient);

- $r=0.7285 \mathrm{~m}$ (turbine radius);

- $a=1.1763 \mathrm{~m}^{2}$ (turbine cross-sectional area);

- $b=0.4 \mathrm{~m}$ (turbine blade height);

- $\quad l=0.3 \mathrm{~m}$ (turbine blade chord length).

The DFIG has the following parameters that are given in the per unit system:

- $\quad P_{\text {nom }}=27 \mathrm{~kW}$ (nominal power);

- $\quad p=4$ (number of poles);

- $\quad L_{s}=0.18 \mathrm{pu}$ (stator inductance);

- $r_{s}=0.023 \mathrm{pu}$ (stator resistance);

- $\quad L_{r}=0.16 \mathrm{pu}$ (rotor inductance);

- $r_{r}=0.016 \mathrm{pu}$ (rotor resistance);

- $\quad L_{m}=2.9 \mathrm{pu}$ (mutual inductance);

- $H=3.65 \mathrm{~s}$ (inertia constant);

- $b=0.01 \mathrm{pu}$ (friction factor).

Simulations were developed with the Matlab/Simulink software and the SimPowerSystems library [35].

In this control scheme validation, an uncertainty of $20 \%$ in the parameters of the system was considered. However, the simulation results show that the proposed control approach is able to cope with this uncertainty without deteriorating the system performance.

The next values for the parameters of the controller are selected: $k=1.56$ and $\gamma=2.34$. These values have been tuned experimentally considering their influence in the performance of 
the proposed control scheme. In this sense, the following rules should be considered in the selection of these parameters. An increase in the parameter $k$ yields a decrease in the speed error convergence time. Unfortunately, this also increases the initial values of the control signal, because in the initial state the error is high, and this is undesirable in real applications. On the other hand, an increase in the parameter $\gamma$ provides a faster adaptation dynamic for the sliding gain. Unfortunately, this also increments the final value of the sliding gain, which is not desirable in real applications.

In the first simulation example, it is considered that the ocean waves produce an oscillation in the pressure drop given by $d P=|7000 \sin (0.1 \pi t)|(\mathrm{Pa})$. This pressure variation is shown in Figure 4 . This value for the pressure drop is considered low because it provides a flow coefficient values below the stalling behavior.

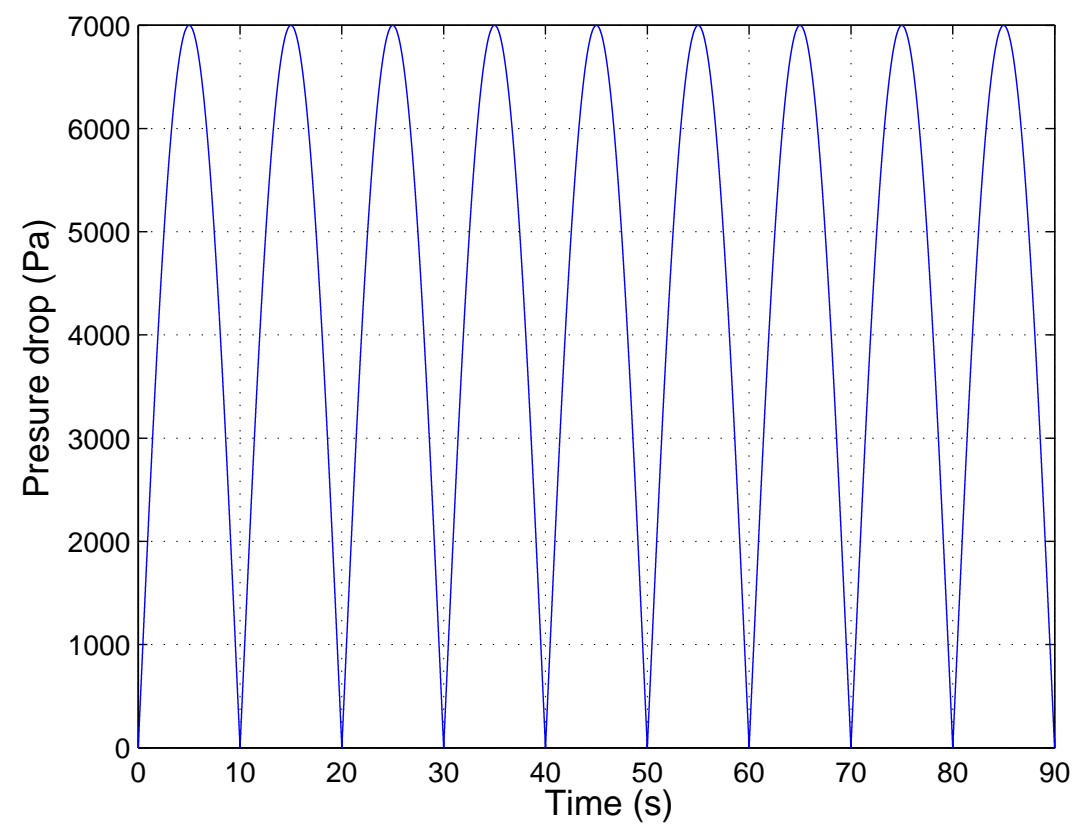

Figure 4. Low pressure drop for the first simulation example.

Figure 5 shows the turbine mechanical power produced by this pressure drop using the proposed adaptive sliding mode control in order to track the turbine speed command that provides the optimum flow coefficient value and hence the maximum power extraction. As can be observed, the average value of the mechanical power produced is $14.2 \mathrm{~kW}$ (green line). Figure 6 shows the electrical power generated whose average value is $10.7 \mathrm{~kW}$ (green line). Figure 7 shows the generator speed whose value is regulated using the proposed adaptive SMC that has been designed in order to optimize the flow coefficient and hence the mechanical power extraction from the Wells turbine system. Figure 8 shows the flow coefficient for this SMC. This figure shows that the speed regulation of the Wells turbine improves the flow coefficient values in order to maximize the mechanical power generation, because the flow coefficient is maintained, almost all of the time, close to the optimum value, $\phi_{\text {opt }}=0.29$, which provides the maximum torque coefficient. It should be noted that the flow coefficient always have to decay to zero due to the oscillatory dynamics of the pressure drop that also decays to zero. However, the SMC tracking control increments the time in which the flow coefficient is maintained close to the optimum value. Figure 9 shows the time evolution of the sliding gain value, which is adapted online in order to overcome the system uncertainties. As can be seen in this figure, the sliding gain value starts from zero increasing its value until the sliding gain is high enough to compensate the uncertainties of the system. Figure 10 shows the sliding variable and Figure 11 shows the control signal. As can be observed, the control signal presents the chattering phenomenon that, as is well known, usually appears in the SMC schemes. However, this chattering will be filtered by the mechanical system inertia 
and it does not present a big problem in this case. Nevertheless, this chattering can be reduced by replacing the sing function with the saturation function [18].

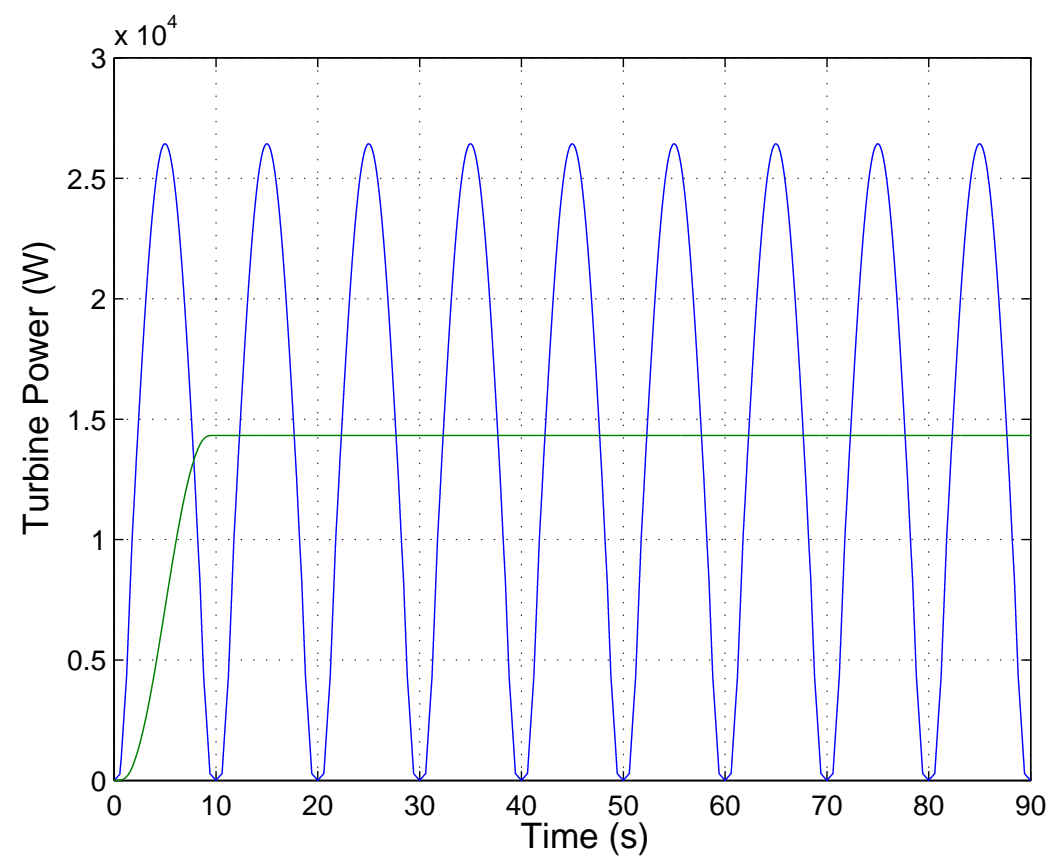

Figure 5. Turbine mechanical power for SMC tracking and low pressure drop.

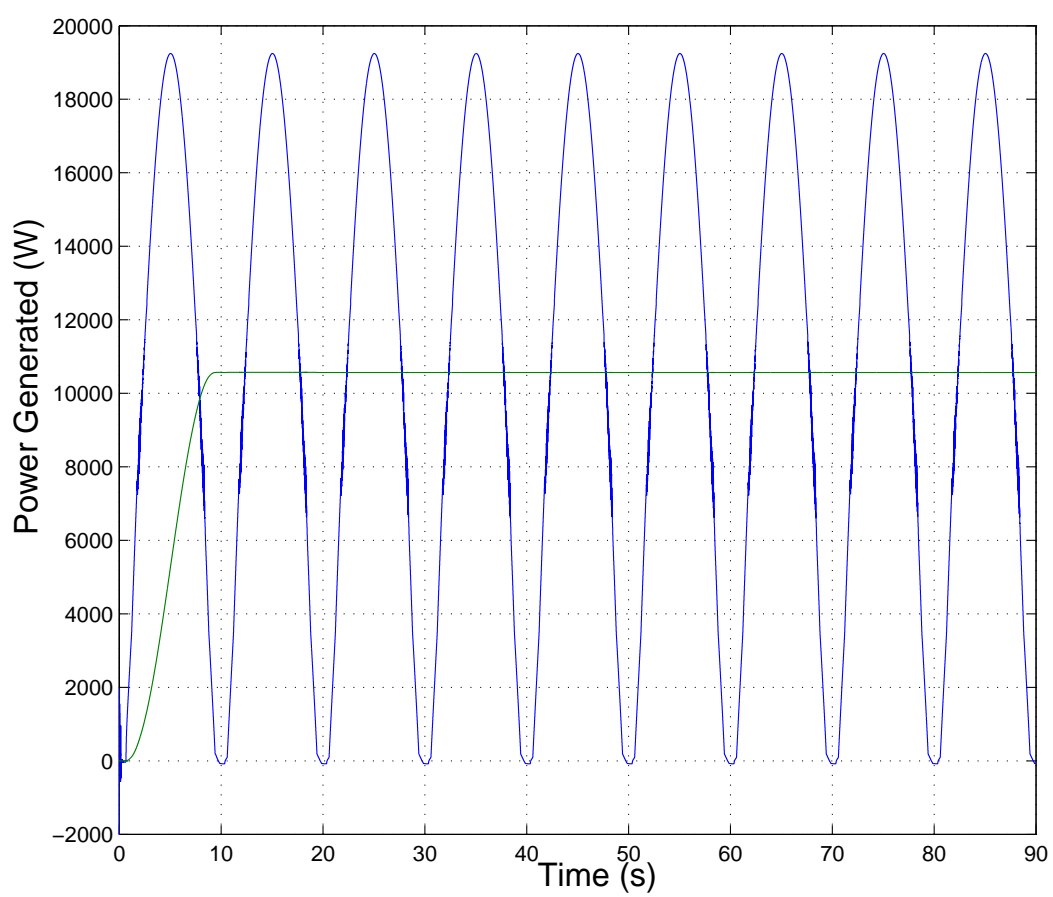

Figure 6. Electrical power generated for SMC tracking and low pressure drop. 


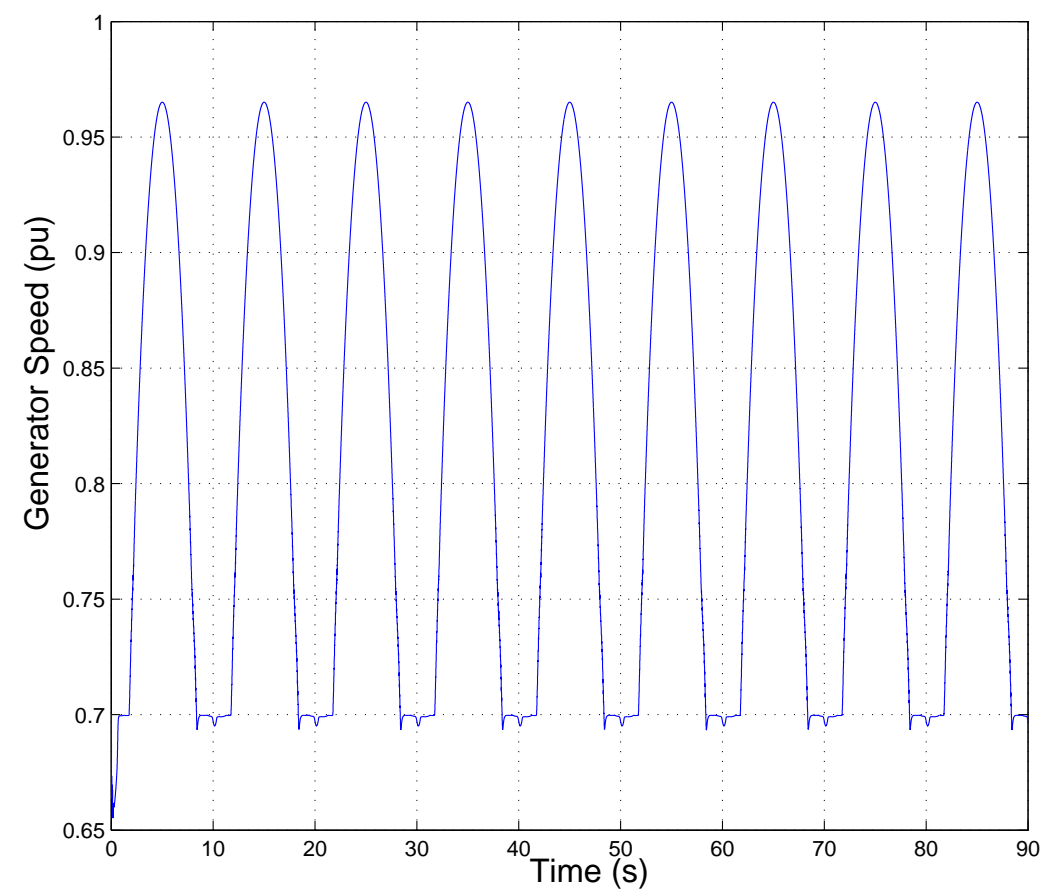

Figure 7. Generator speed for SMC tracking and low pressure drop.

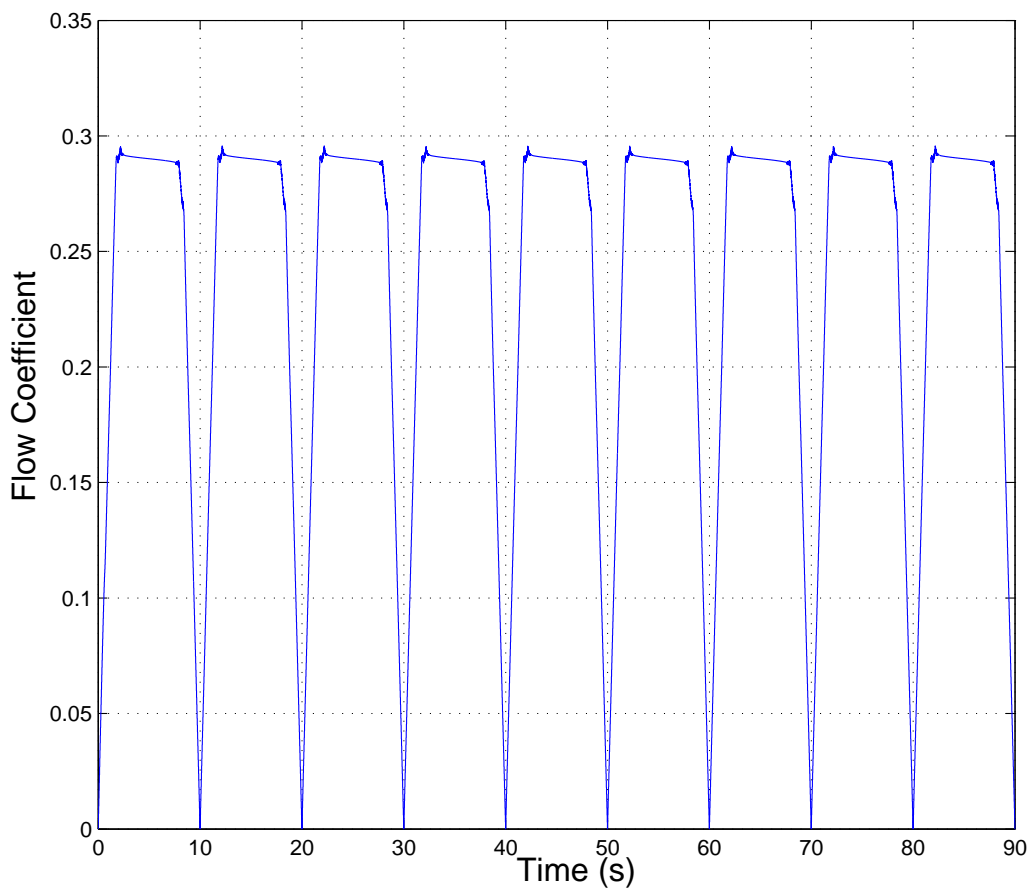

Figure 8. Flow coefficient for SMC tracking and low pressure drop. 


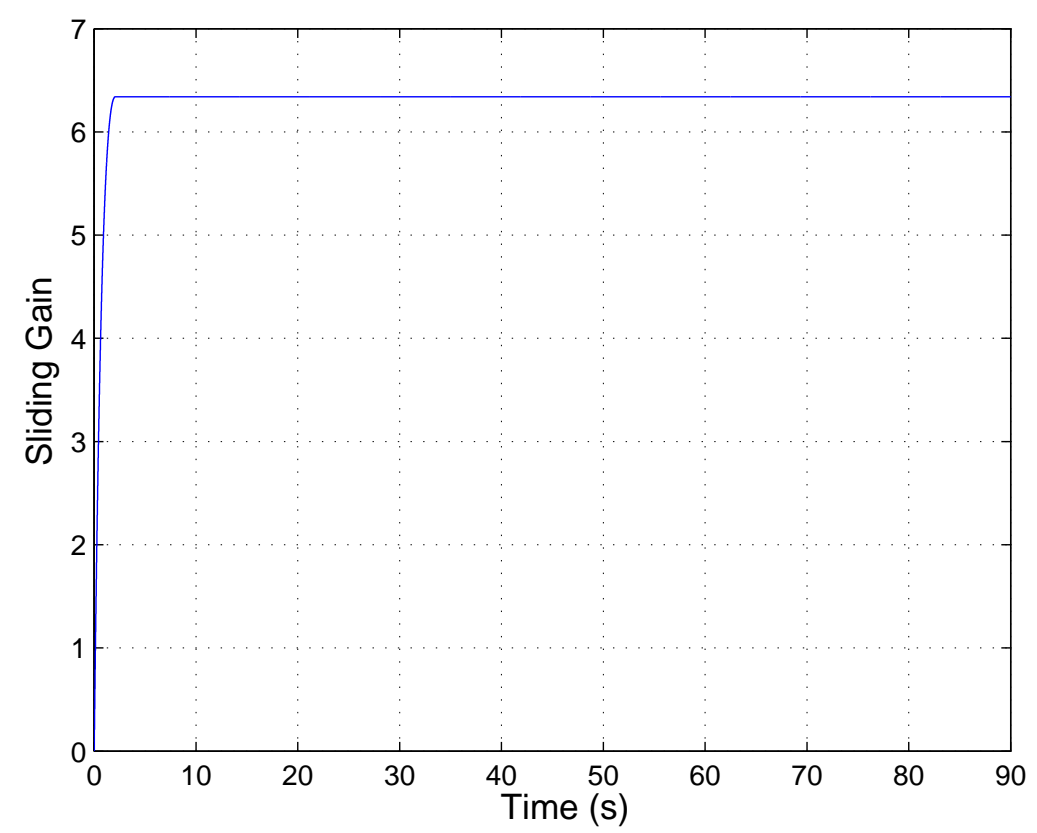

Figure 9. Sliding gain adaptation for SMC tracking and low pressure drop.

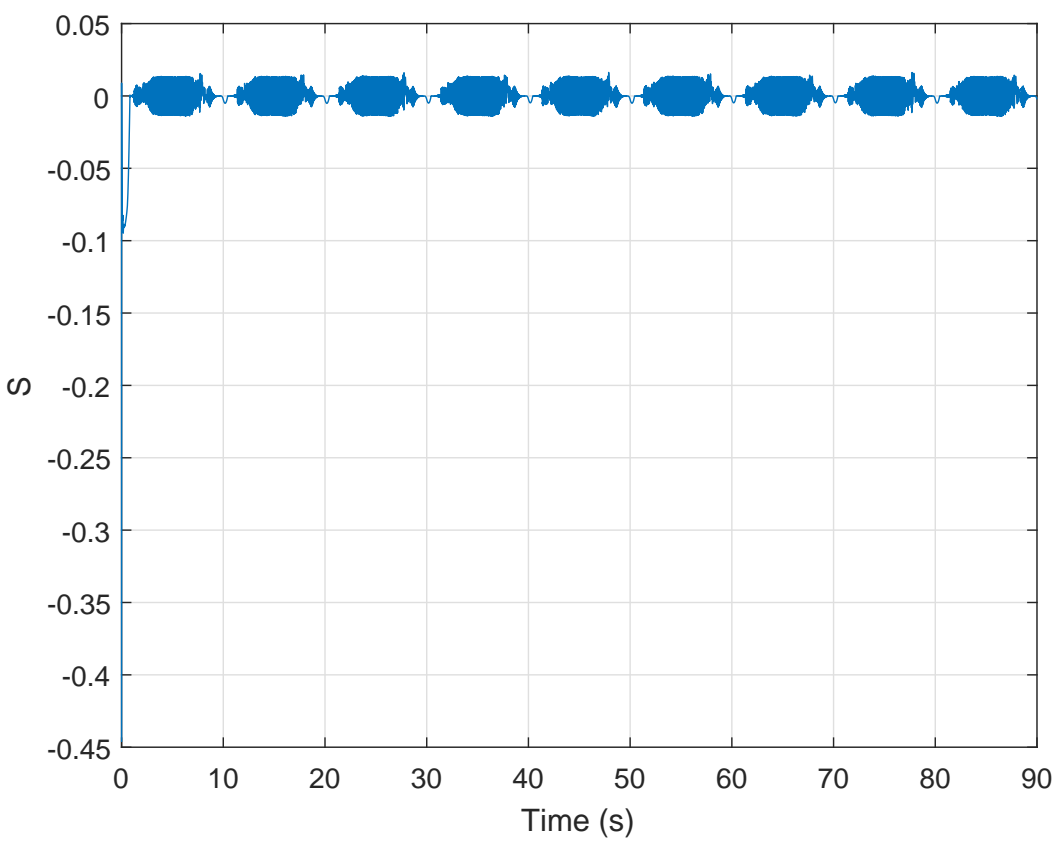

Figure 10. Sliding variable for SMC tracking and low pressure drop.

Figure 12 shows the turbine mechanical power produced by this pressure drop for this system without optimum tracking control; that is, in this case the turbine speed does not follow the reference value that provides the optimum flow coefficient. The average value of the mechanical power produced in this case is $10.8 \mathrm{~kW}$ (green line). Figure 13 shows the electrical power generated whose average value is $8.2 \mathrm{~kW}$ (green line). Figure 14 shows the flow coefficient obtained for this system without optimum tracking control. In this figure, it can be observed that the flow coefficient is not optimized in order to increment the mechanical power generation, and the flow coefficient is therefore not maintained close to the optimum value $\phi_{o p t}=0.29$. In this case, without optimum tracking control, the dynamics of the flow coefficient follows the oscillatory dynamics of the pressure drop. 
Therefore, comparing Figures 6 and 13, it can be observed that the electrical power generated by an OWC-based wave power generation plat can be improved by controlling the generator speed in order to obtain the optimum flow coefficient value for the Wells turbine that produces the maximum wave energy extraction.

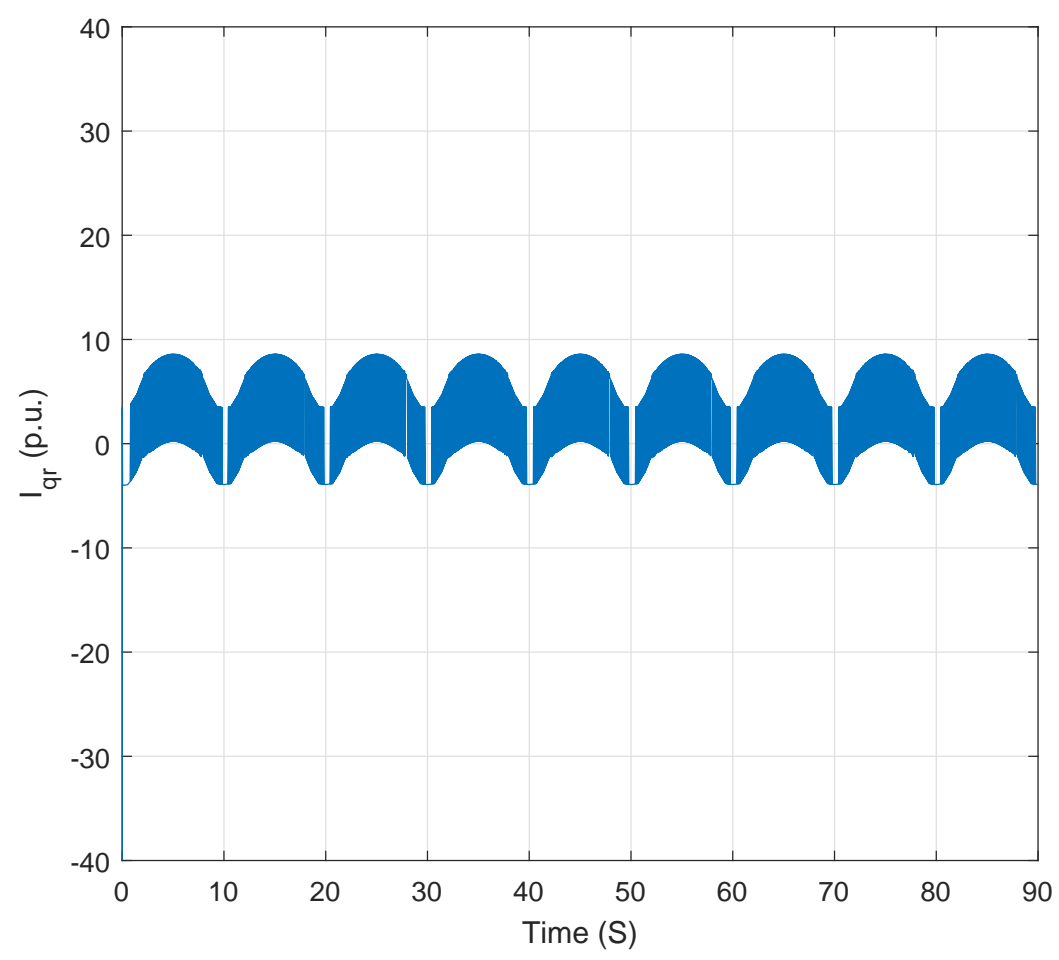

Figure 11. Control signal $\left(i_{q r}\right)$ for SMC tracking and low pressure drop.

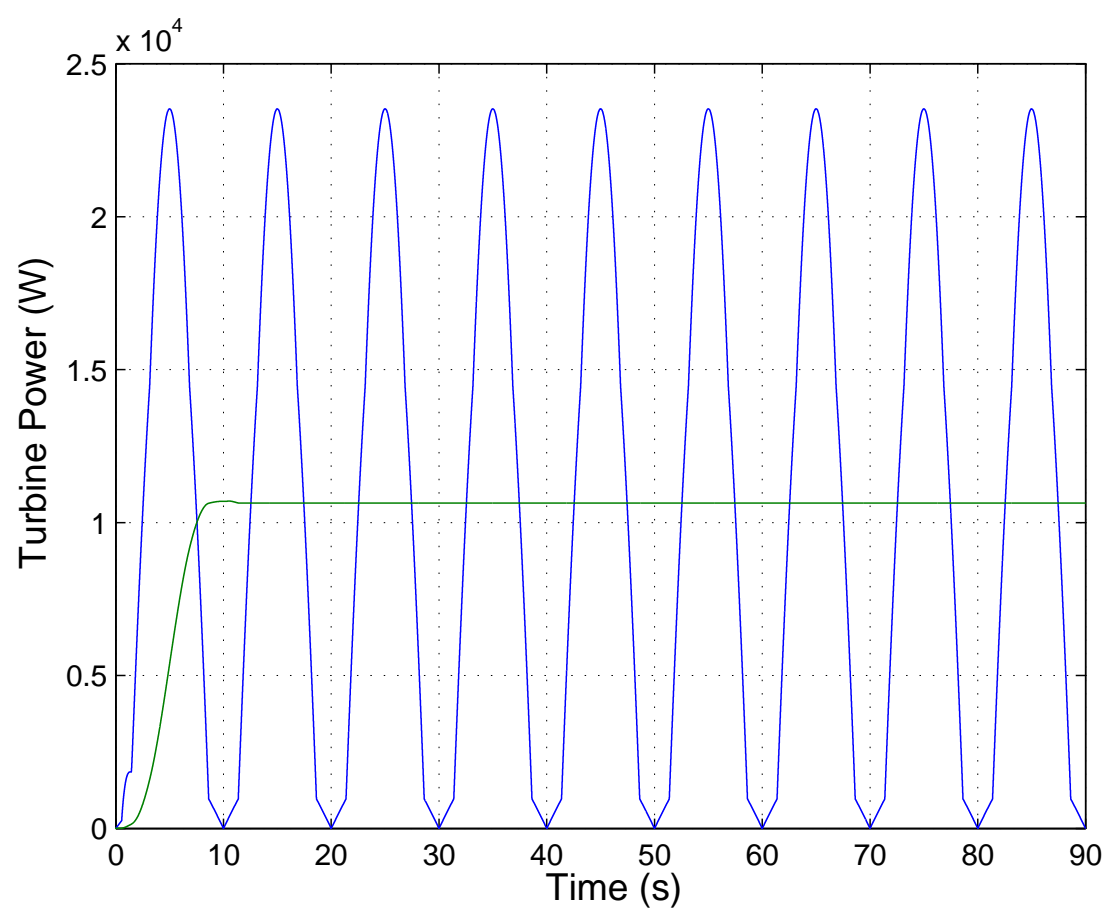

Figure 12. Turbine mechanical power without tracking and low pressure drop. 
In the second simulation example, it is considered that the ocean waves produce an oscillation in the pressure drop given by $d P=|10,000 \sin (0.1 \pi t)|(\mathrm{Pa})$. This pressure variation is shown in Figure 15 . This value for the pressure drop is considered high because it provides a flow coefficient that reaches the stalling behavior.

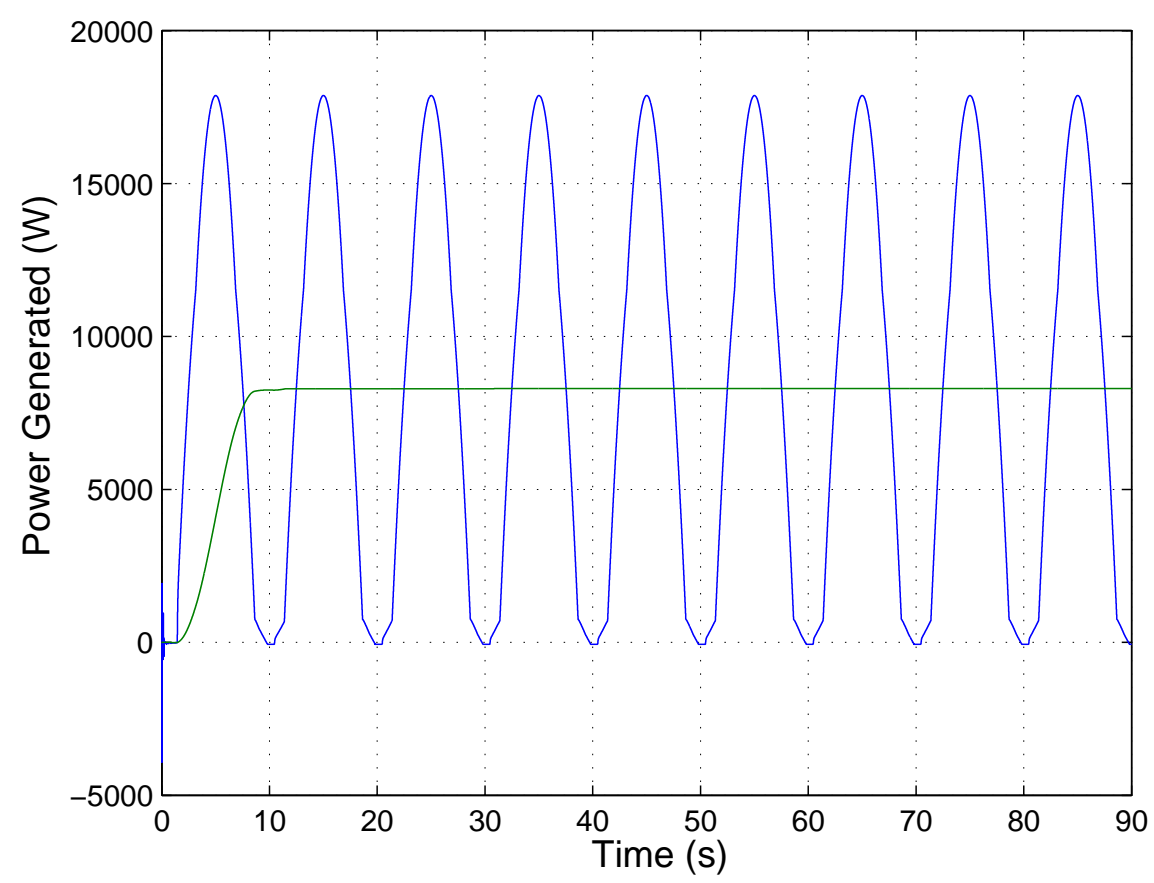

Figure 13. Electrical power generated without tracking and low pressure drop.

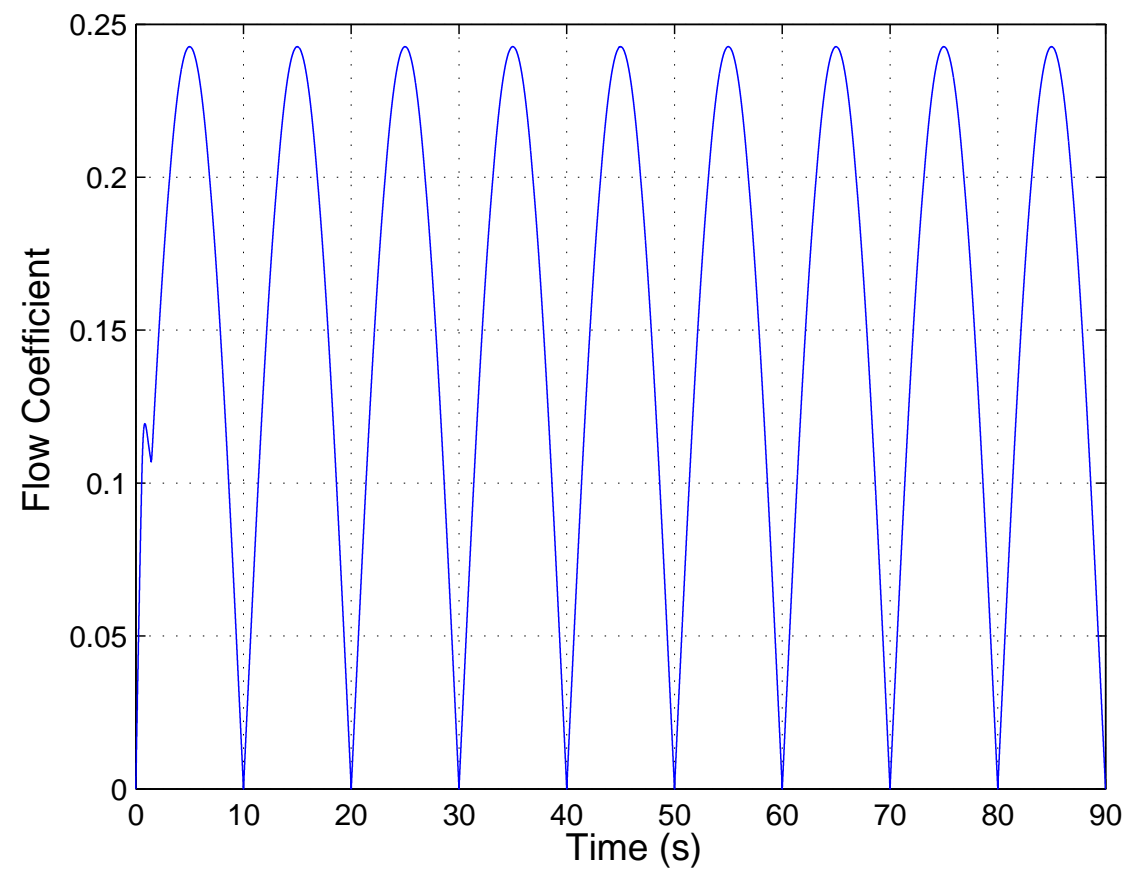

Figure 14. Flow coefficient without tracking and low pressure drop. 
Figure 16 shows the turbine mechanical power produced by this pressure drop using this adaptive $\mathrm{SMC}$. The average value of the mechanical power produced is $24.9 \mathrm{~kW}$ (green line). Figure 17 shows the electrical power generated whose average value is $18.3 \mathrm{~kW}$ (green line). Figure 18 shows the generator speed whose value is regulated by this adaptive sliding mode control in order to optimize the mechanical power extraction from the Wells turbine system.

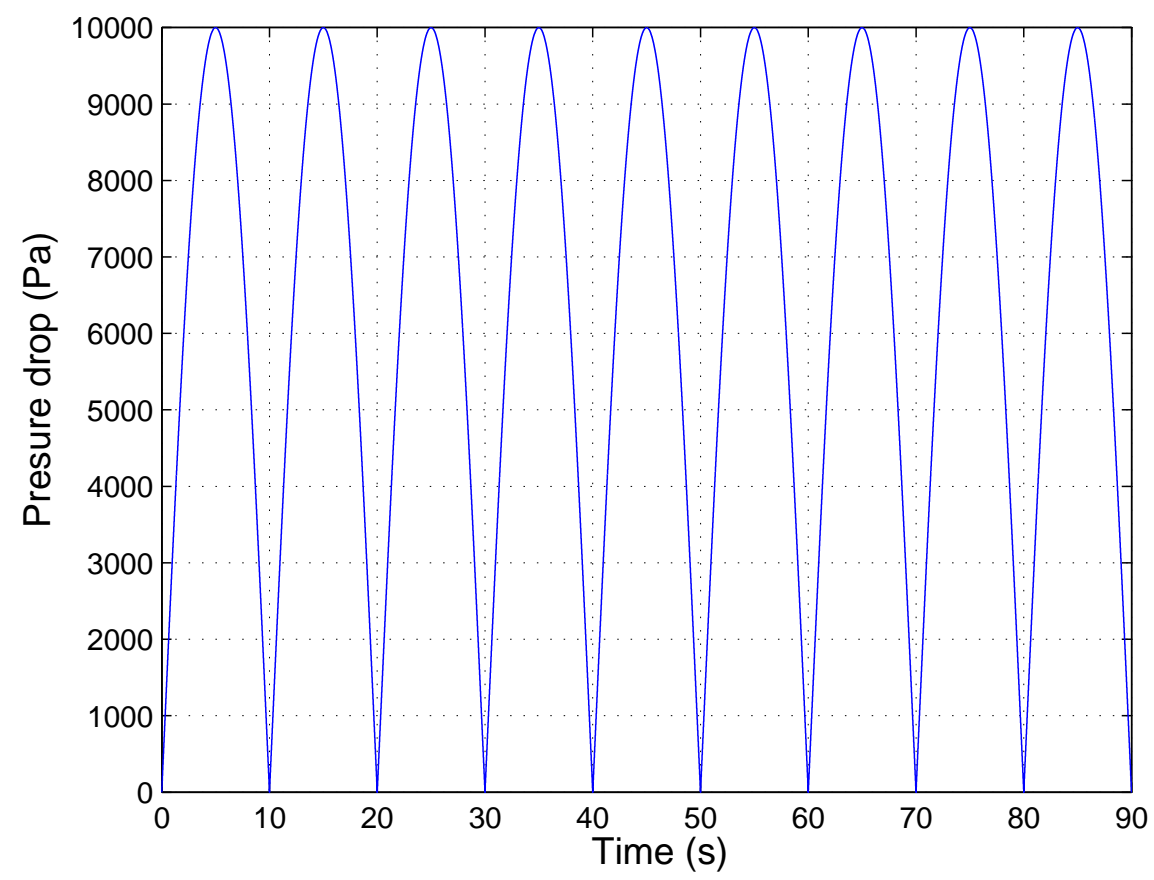

Figure 15. High pressure drop for the second simulation example.

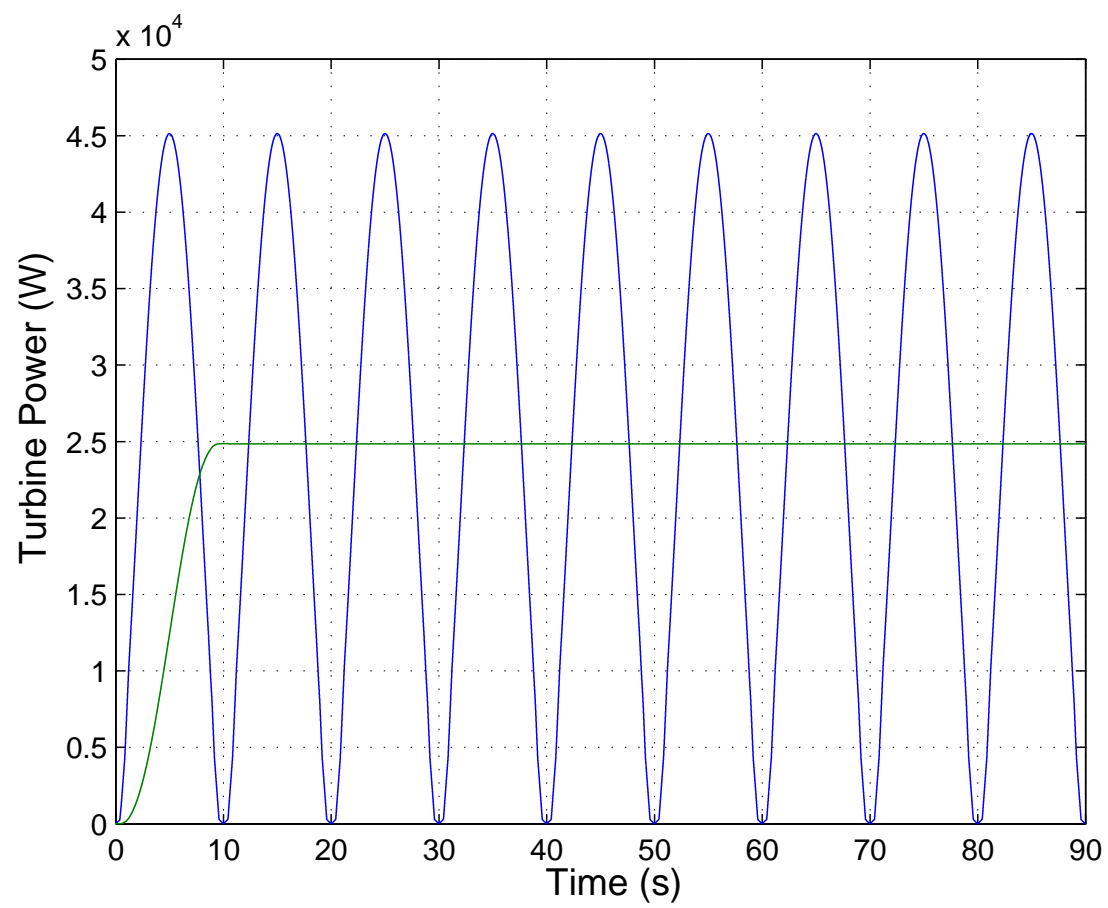

Figure 16. Turbine mechanical power for SMC tracking and high pressure drop. 


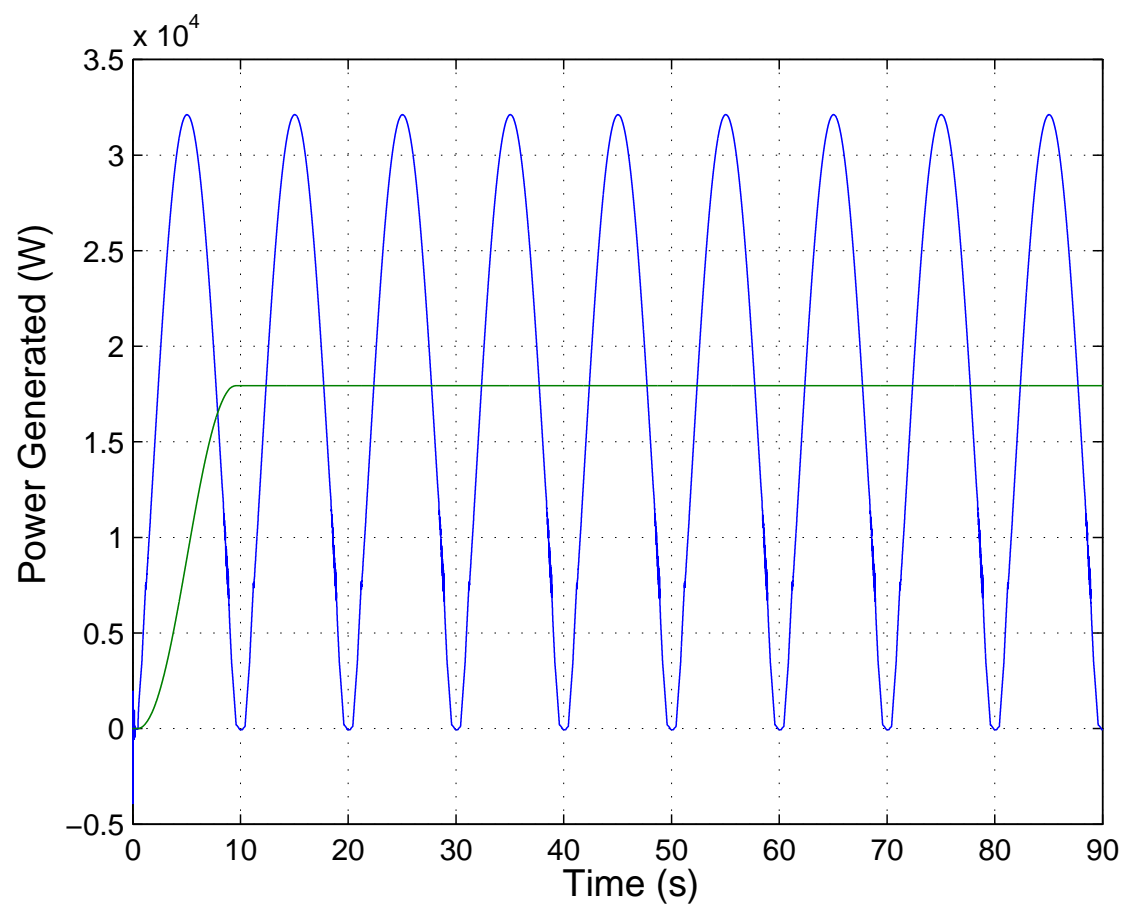

Figure 17. Electrical power generated for SMC tracking and high pressure drop.

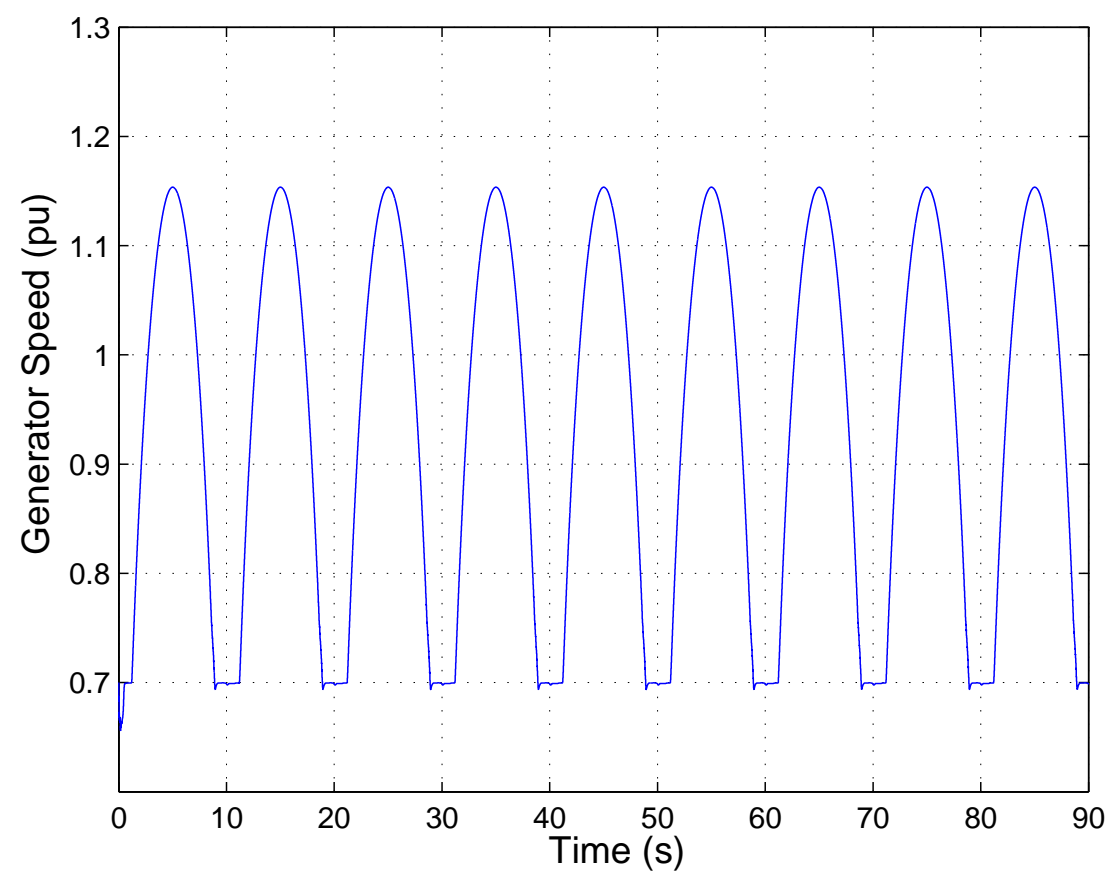

Figure 18. Generator speed for SMC tracking and high pressure drop.

Figure 19 shows the flow coefficient for the SMC case where the flow coefficient is maintained close to the optimum value. This figure shows that the speed regulation of the Wells turbine improves the flow coefficient values and hence optimizes the mechanical power generation. Moreover, the proposed speed regulation also avoids the stalling behavior that usually happens in the Wells turbine because the flow coefficient is maintained below the critical value $\phi=0.3$. Figure 20 shows the sliding gain value that is adapted online in order to compensate the system uncertainties. As in the previous example, the 
sliding gain value is incremented until the value of the sliding gain can compensate the uncertainties of the system. Figure 21 shows the sliding variable and Figure 22 shows the control signal.

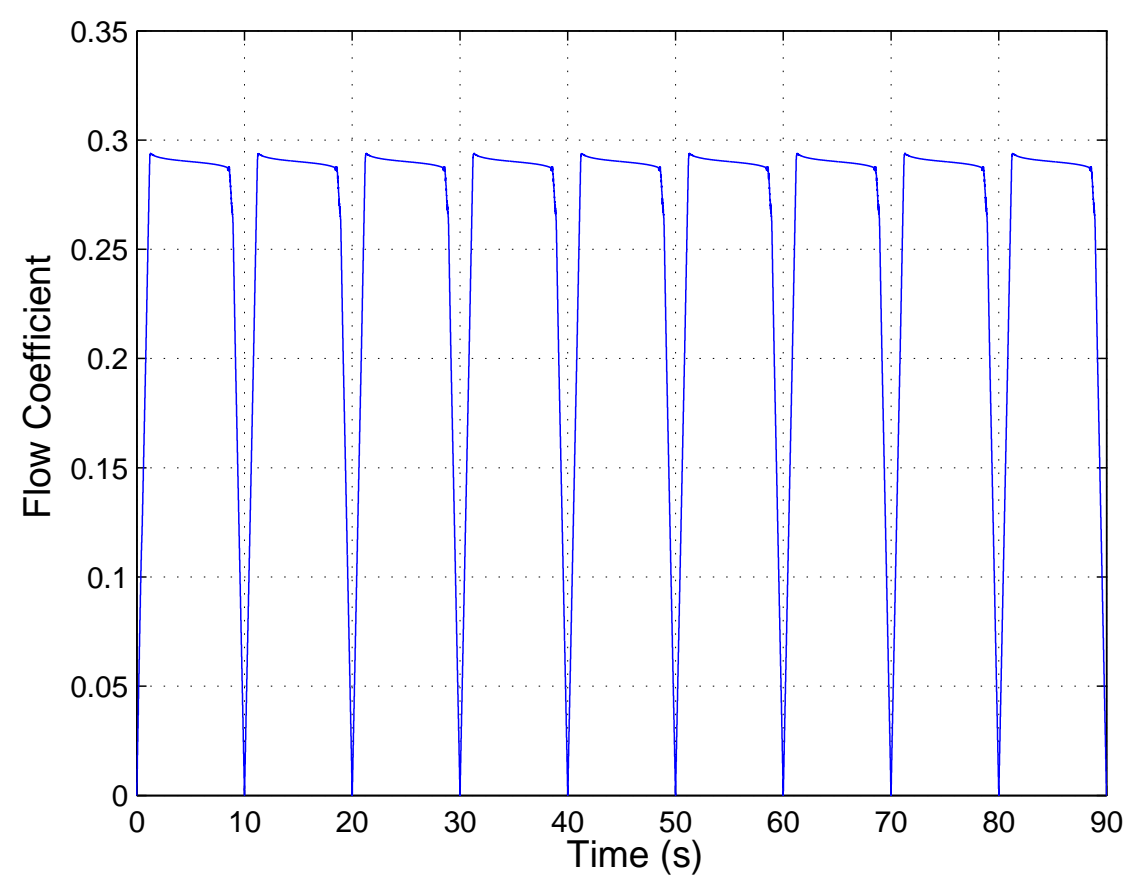

Figure 19. Flow coefficient for SMC tracking and high pressure drop.

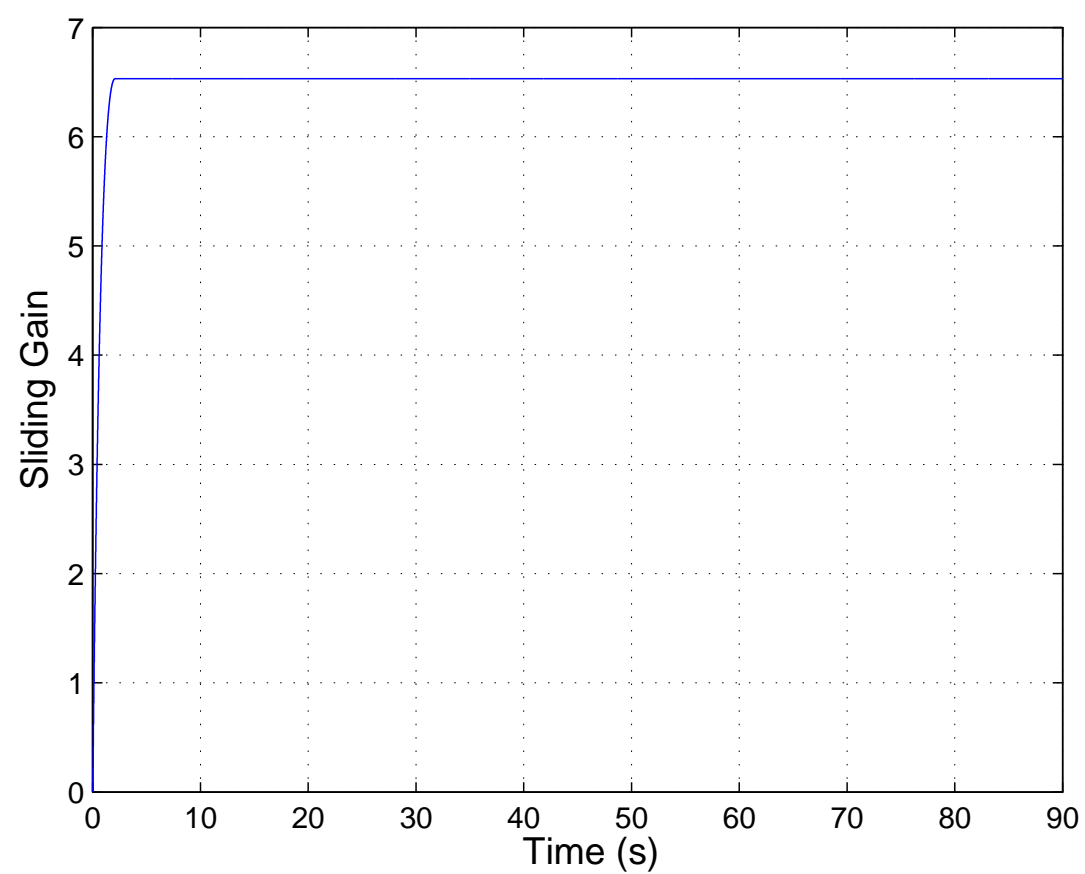

Figure 20. Sliding gain adaptation for SMC tracking and high pressure drop. 


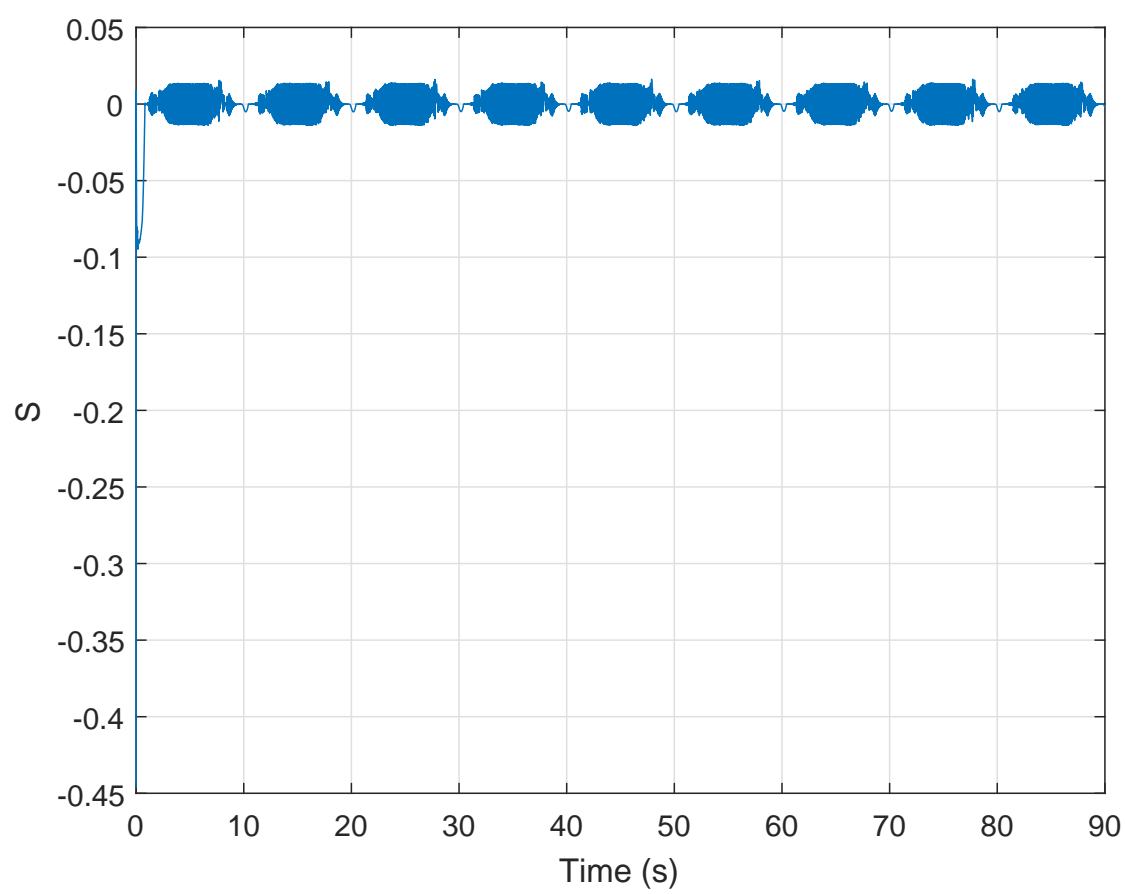

Figure 21. Sliding variable for SMC tracking and high pressure drop.

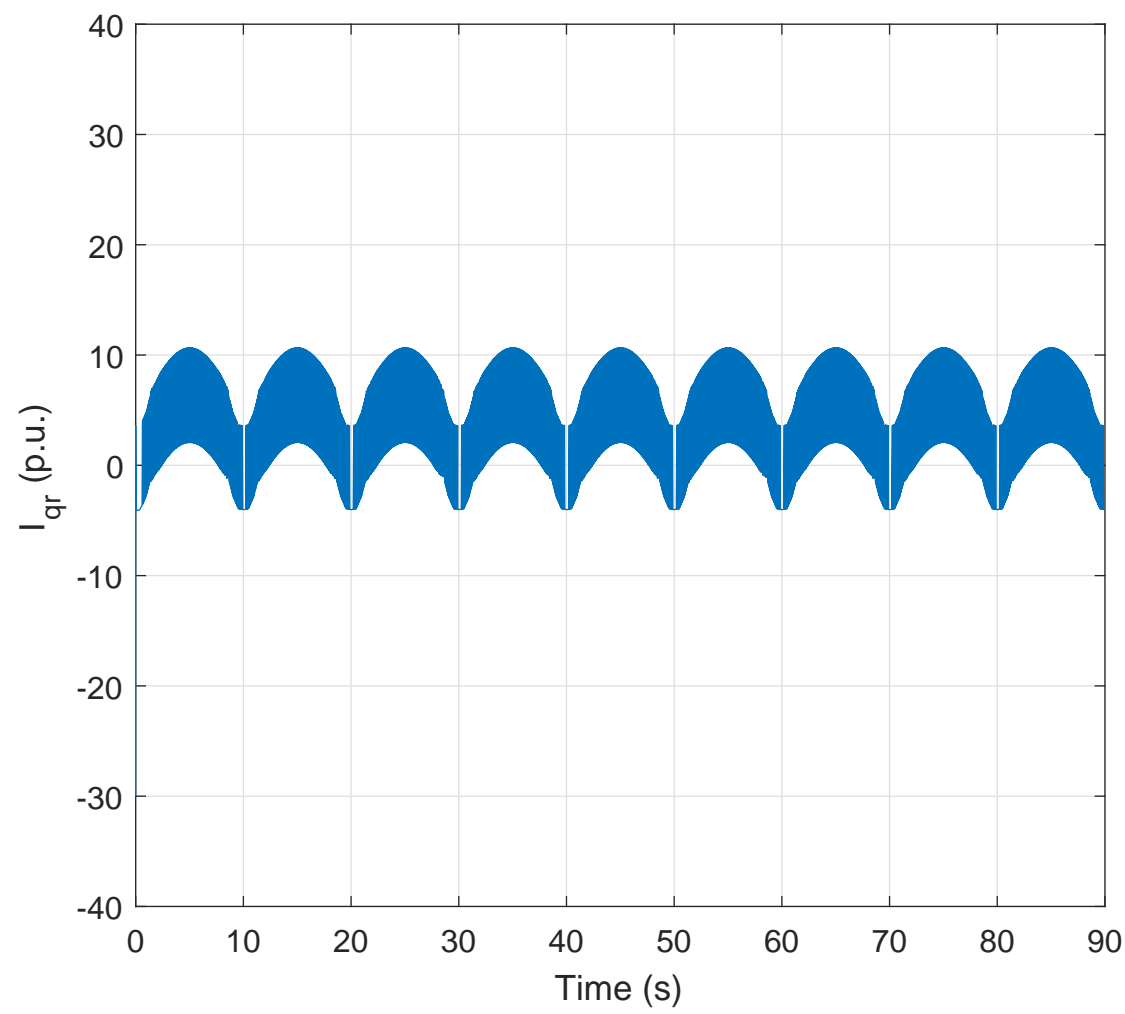

Figure 22. Control signal $\left(i_{q r}\right)$ for SMC tracking and high pressure drop.

Figure 23 shows the turbine mechanical power produced by this pressure drop for this system without optimum tracking control. Unlike the previous optimum tracking SMC, the undesirable stalling behavior that produces power losses can be observed in this figure. The average value of the 
mechanical power produced in this case is $17.3 \mathrm{~kW}$ (green line). Figure 24 shows the electrical power generated whose average value is $12.9 \mathrm{~kW}$ (green line).

Figure 25 shows the flow coefficient for the case without optimum tracking control. In this figure, it can be seen that the flow coefficient exceeds the critical value $\phi=0.3$, and the stalling behavior therefore appears in the dynamics of the Wells turbine because the flow coefficient is not optimized in order to increment the mechanical power generation.

Comparing Figures 17 and 24, it can be observed that the electrical power generated by an OWC system can be improved in two ways by means of the generator speed control. On the one hand, the optimum speed tracking improves the OWC system performance providing an optimum value of the flow coefficient for the Wells turbine that produces the maximum mechanical energy extraction from the ocean waves. On the other hand, the optimum speed tracking can also be used to avoid the stalling behavior in the Wells turbine dynamics, because the flow coefficient can be maintained below the critical value $\phi=0.3$.

In the next simulation example, the proposed control scheme is evaluated under irregular waves. In this case, these irregular waves produce the pressure drop profile shown in Figure 26.

Figure 27 shows the turbine mechanical power produced by this pressure drop using the proposed control scheme. In this figure, the green line shows the average value of the produced mechanical power. Figure 28 shows the electrical power generated, and the average value of this power is also shown in the green line. Figure 29 shows the generator speed whose value is regulated by this adaptive SMC in order to optimize the mechanical power extraction from the Wells turbine system.

Figure 30 shows the flow coefficient for the SMC case under irregular waves scenario. This figure shows that the speed regulation of the Wells turbine improves the flow coefficient values and hence optimizes the mechanical power generation. Moreover, the proposed speed regulation also avoids the stalling behavior that usually happens in the Wells turbine because the flow coefficient is maintained below the critical value $\phi=0.3$.

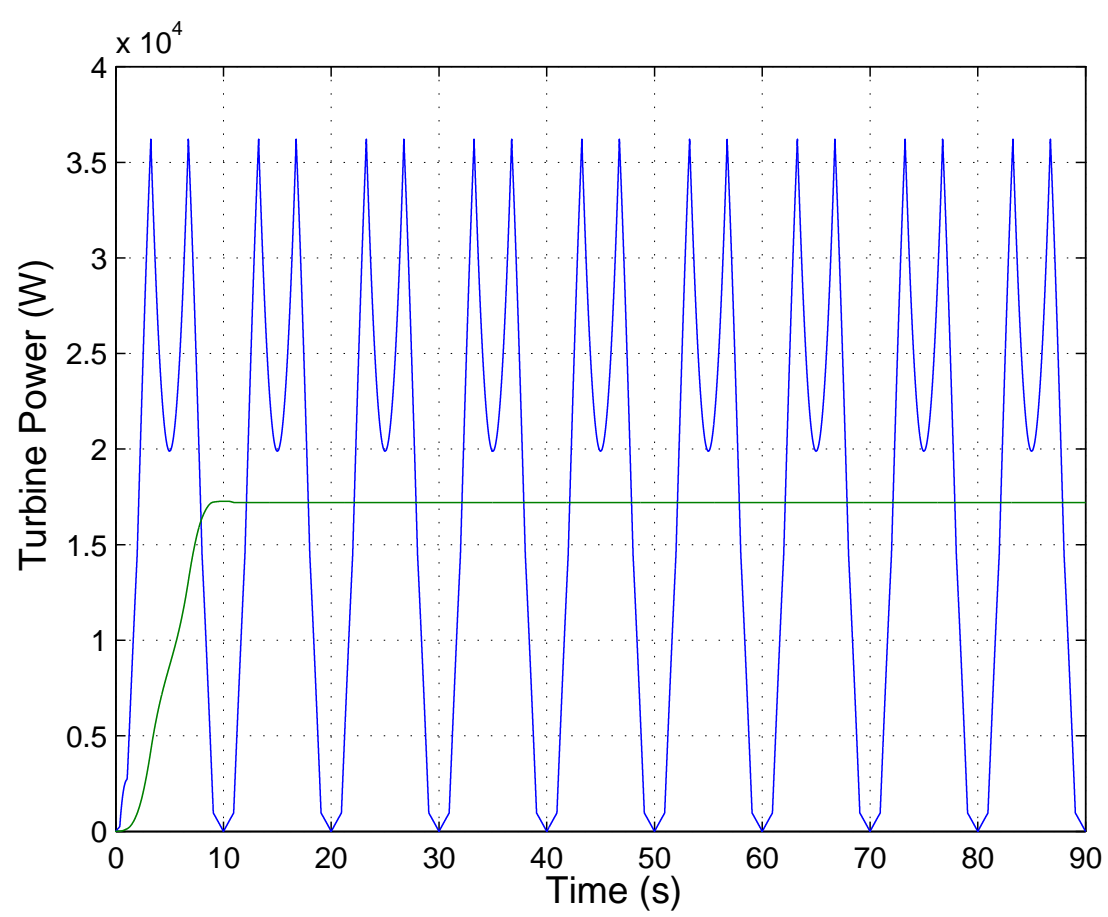

Figure 23. Turbine mechanical power without tracking and high pressure drop. 


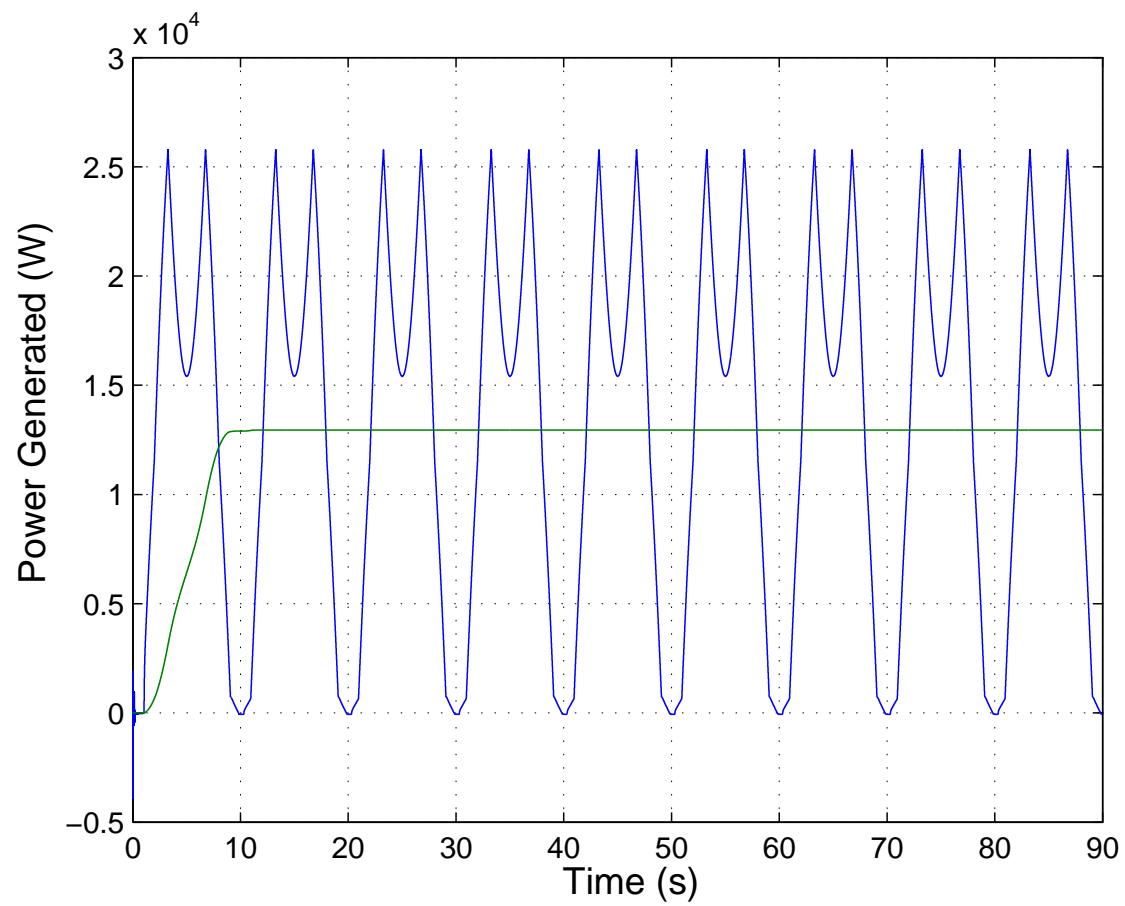

Figure 24. Electrical power generated without tracking and high pressure drop.

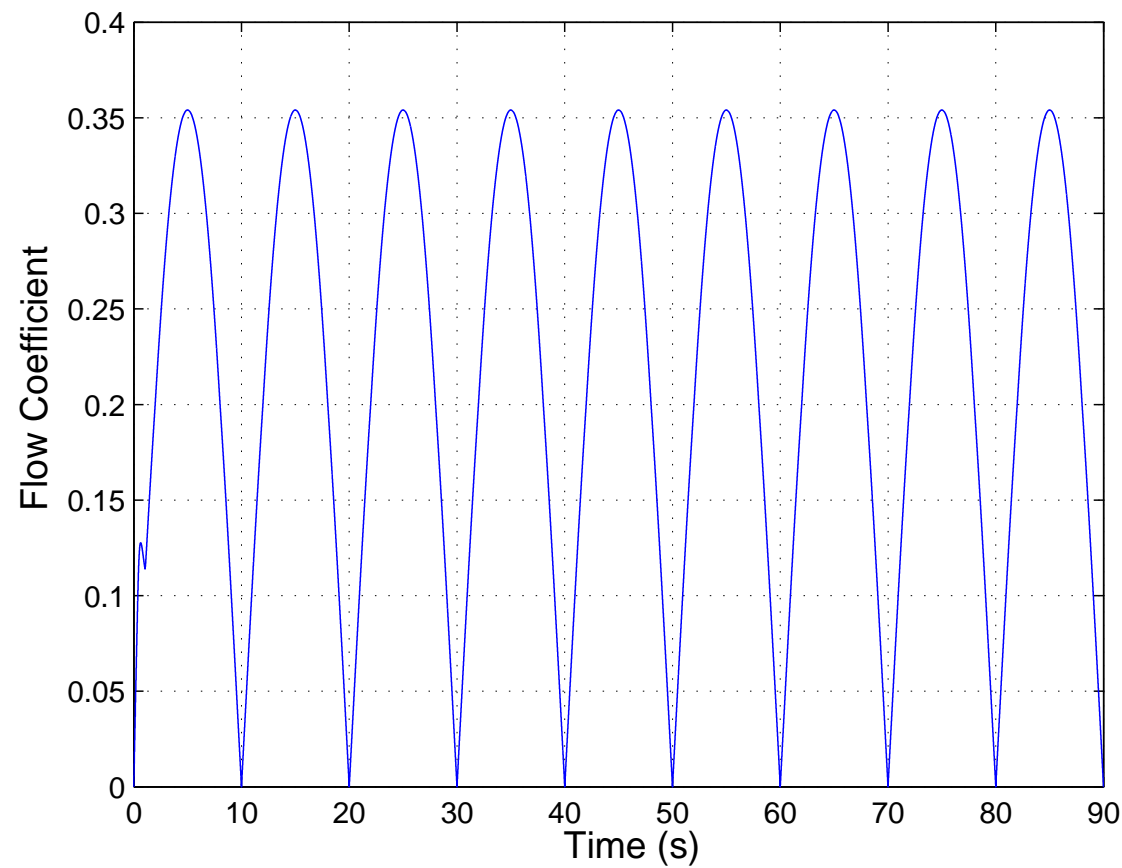

Figure 25. Flow coefficient without tracking and high pressure drop. 


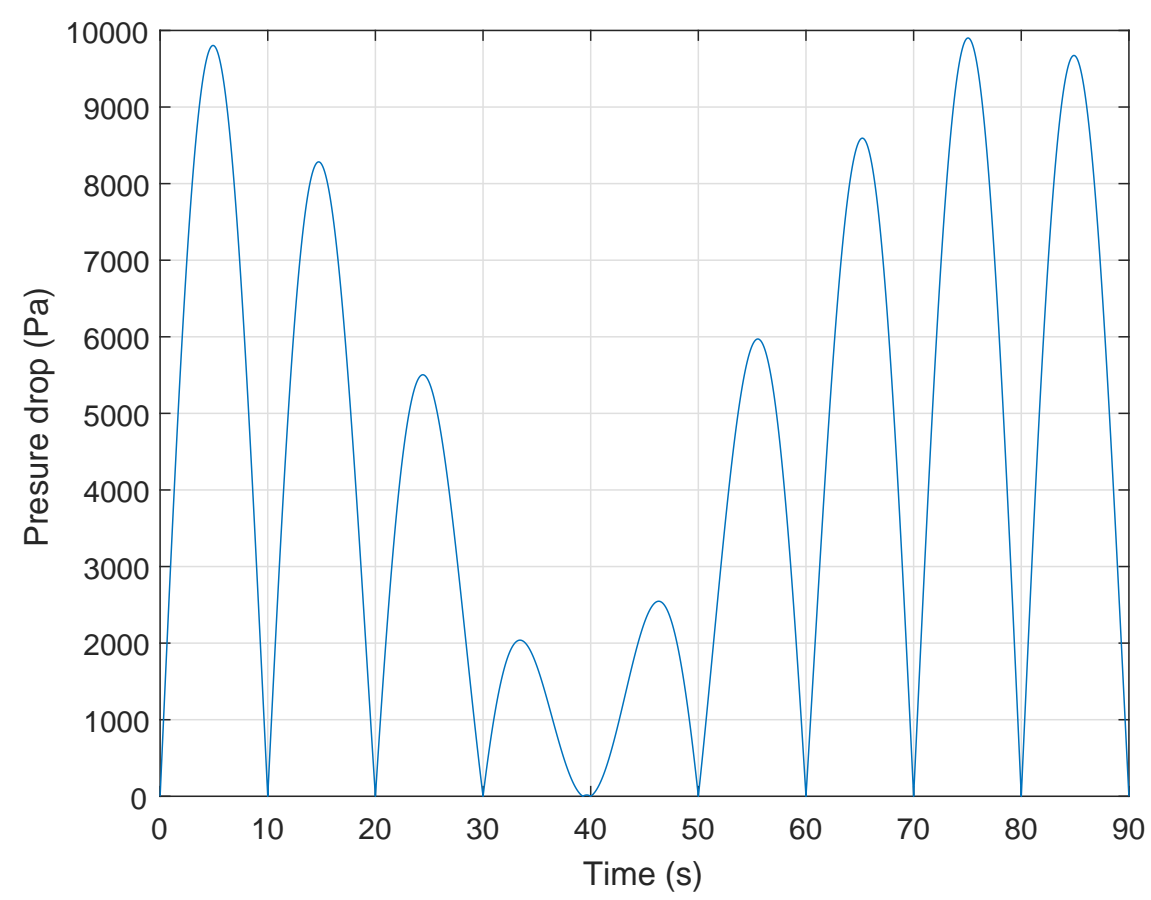

Figure 26. Pressure drop for the case of irregular waves.

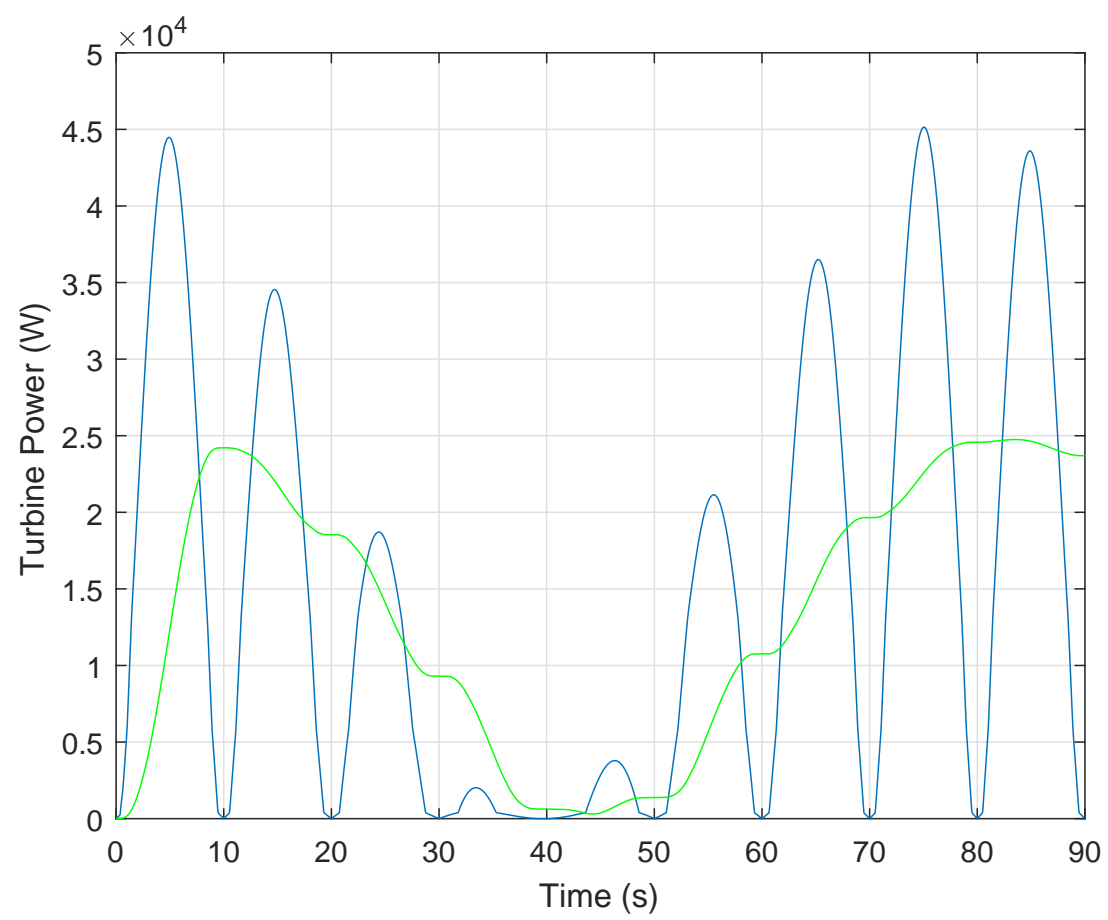

Figure 27. Turbine mechanical power for SMC tracking and irregular waves. 


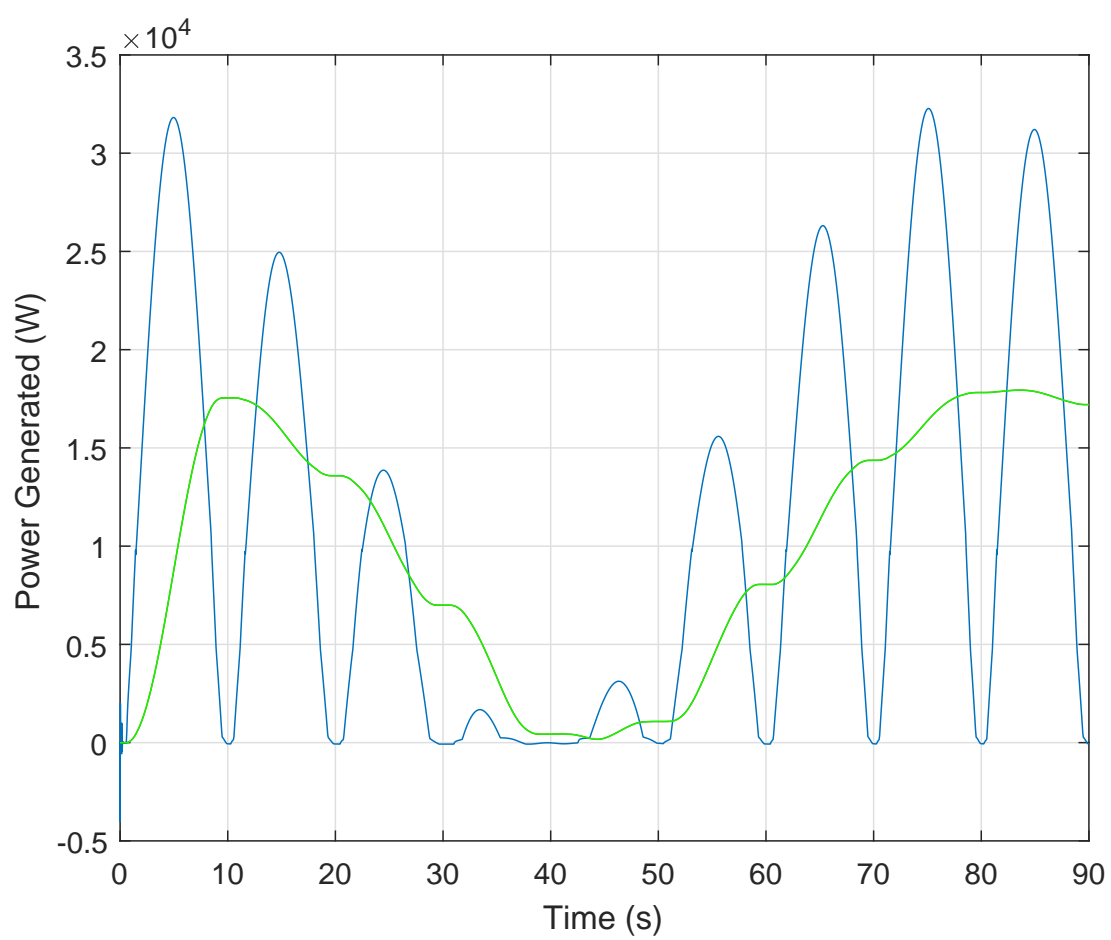

Figure 28. Electrical power generated for SMC tracking and irregular waves.

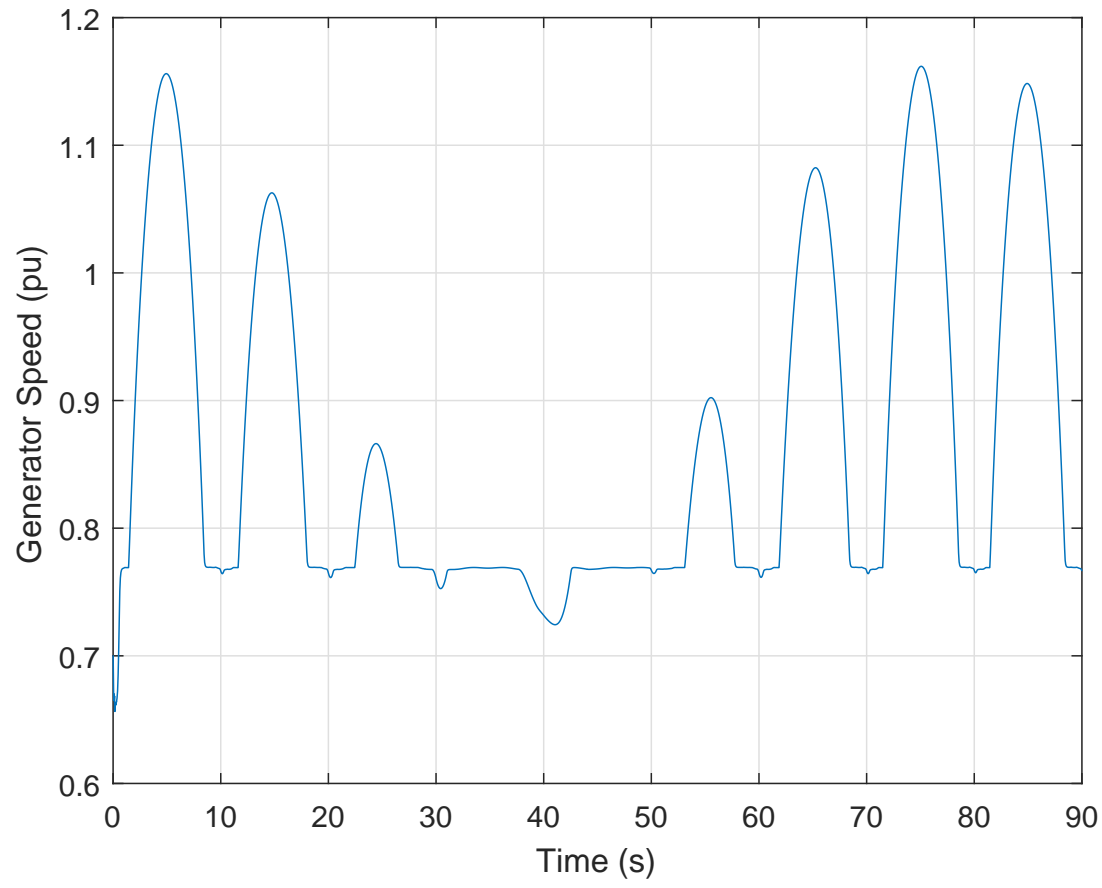

Figure 29. Generator speed for SMC tracking and irregular waves. 


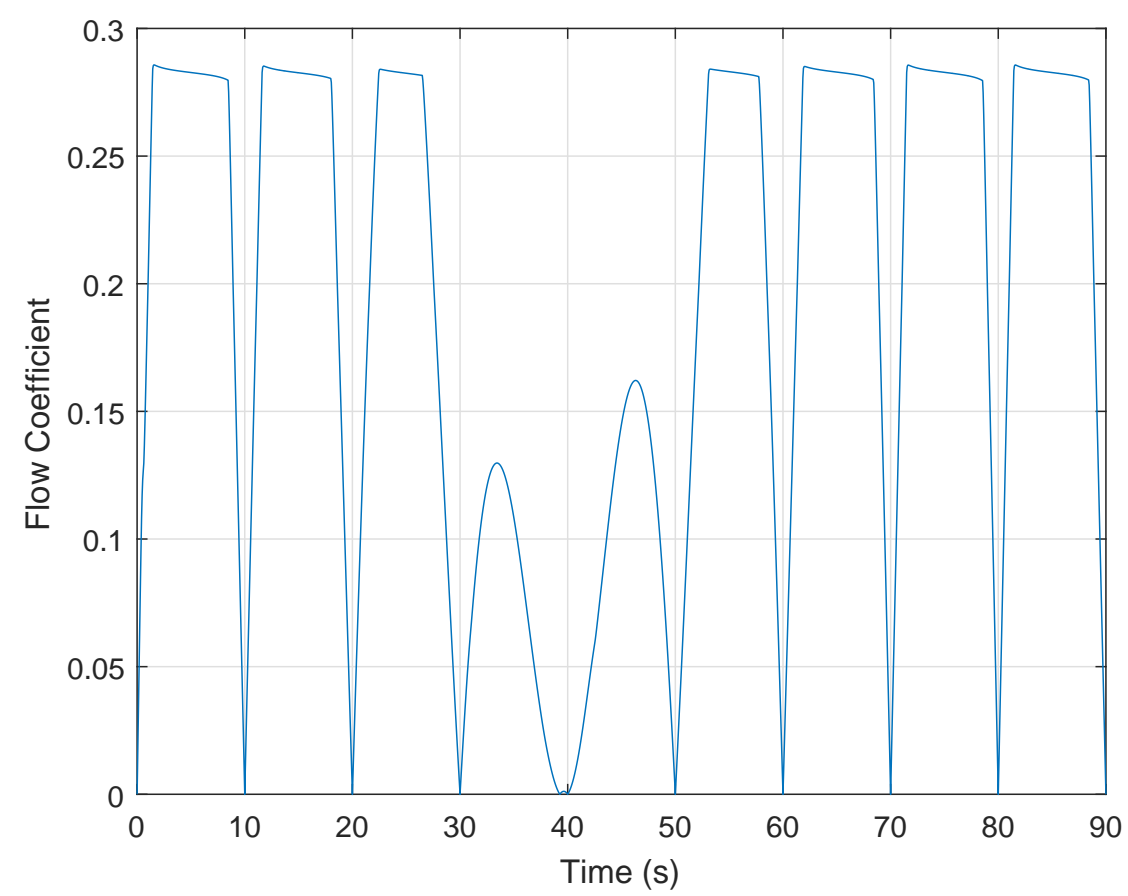

Figure 30. Flow coefficient for SMC tracking and irregular waves.

\section{Conclusions}

In this work, an adaptive SMC scheme for OWC wave power generation plants is proposed. It is assumed that the OWCs use Wells turbines and DFIGs. The SMC technique is inherently robust, so its application in such plants may reduce the effect of the uncertainties caused by the errors in the model of the plant as well as the disturbances of the system. However, in traditional SMC control schemes, it is necessary to calculate an upper limit for the system uncertainties in order to obtain an adequate value for the sliding gain. The SMC control scheme proposed in this work copes with this drawback by means of an adaptive switching gain value that can be calculated online. This work also analyzes the response and robustness of the proposed adaptive SMC, and it is concluded that the SMC is robust and presents a good dynamic response under system disturbances and modeling uncertainties.

Since the closed-loop stability of the proposed control scheme must be ensured, the Lyapunov stability theory was employed. The proposed design for the controller was successfully validated through several simulation examples with the Matlab/Simulink suite. Moreover, this work introduces a method to achieve the optimal flow coefficient value, while avoiding the stalling behavior. As a result, the Wells turbine is able to maximize the extraction of mechanical power from the ocean waves and, consequently, generate the maximum electrical power, improving the performance of the OWC-based wave power generation plans. The results of the simulations proved that the proposed adaptive SMC scheme adequately regulates the turbine speed command and therefore the optimum flow coefficient value; hence, the maximum power extraction can be obtained.

Author Contributions: This work was led by O.B. The theoretical development was performed by O.B. The modeling process was performed by O.B. and J.M.G.d.D. Simulation and analysis of the results was performed by O.B., J.M.G.d.D., and I.C. O.B., J.M.G.d.D., and I.C. participated in the writing, review, and editing of the manuscript. The final version was revised and has been approved by all the authors.

Funding: This research was partially funded by the Basque Government through the project ETORTEK KK-2017/00033 and by the UPV/EHU through the project PPGA18/04.

Acknowledgments: The authors wish to express their gratitude to the UPV/EHU and the Basque Government for supporting this work through the projects PPGA18/04 and ETORTEK KK-2017/00033.

Conflicts of Interest: The authors declare no conflict of interest. 


\section{Abbreviations}

The following variables and symbols are used in this manuscript:

\begin{tabular}{|c|c|}
\hline$v_{x}$ & Airflow speed \\
\hline$d P$ & Pressure drop across the turbine \\
\hline$a$ & Area of turbine duct \\
\hline$\phi$ & Flow coefficient \\
\hline$T_{t}$ & Torque generated by the Wells turbine \\
\hline$C_{t}$ & Torque coefficient \\
\hline$C_{a}$ & Power coefficient \\
\hline$k_{t}$ & Turbine constant \\
\hline$v_{x}$ & Air flow velocity \\
\hline$r$ & Turbine radius \\
\hline$w$ & Turbine angular velocity \\
\hline$n$ & Number of blades \\
\hline$b$ & Blade height \\
\hline$l$ & Blade chord length \\
\hline$a$ & Turbine cross-sectional area \\
\hline$q$ & Flow rate \\
\hline$\eta$ & Turbine efficiency \\
\hline$B$ & Viscous friction coefficient \\
\hline$T_{e}$ & Generator torque \\
\hline$J$ & Inertia moment \\
\hline$w$ & Angular velocity of the turbine shaft \\
\hline$w_{e}$ & Angular velocity of the generator rotor \\
\hline$i_{q s}$ and $i_{d s}$ & $\mathrm{q}$-d components of the stator current \\
\hline$i_{q r}$ and $i_{d r}$ & $\mathrm{q}$-d components of the rotor current \\
\hline$L_{s}, L_{r}$, and $L_{m}$ & Stator inductance, rotor inductance and mutual inductances \\
\hline$i_{m s}$ & Stator magnetizing current \\
\hline$w_{S}$ & Rotational speed of the synchronous reference frame \\
\hline$s w_{s}=w_{s}-w_{e}$ & Slip frequency \\
\hline$w_{e}$ & Generator rotor speed \\
\hline$v_{q r}$ and $v_{d r}$ & $\mathrm{q}-\mathrm{d}$ components of the rotor voltage \\
\hline$p$ & Pole numbers \\
\hline$\hat{\beta}$ & Estimated switching gain \\
\hline$S$ & Sliding variable \\
\hline$k$ & Positive constant (controller parameter) \\
\hline$\gamma$ & Positive constant (controller parameter) \\
\hline
\end{tabular}

\section{References}

1. Wan, Y.; Fan, C.; Zhang, J.; Meng, J.; Dai, Y.; Li, L.; Sun, W.; Zhou, P.; Wang, J.; Zhang, X. Wave Energy Resource Assessment off the Coast of China around the Zhoushan Islands. Energies 2017, 10, 1320. [CrossRef]

2. Wan, Y.; Fan, C.; Dai, Y.; Li, L.; Sun, W.; Zhou, P.; Qu, X. Assessment of the Joint Development Potential of Wave and Wind Energy in the South China Sea. Energies 2018, 11, 398. [CrossRef]

3. Wu, W.C.; Yang, Z.Q.; Wang, T.P. Wave resource characterization using an unstructured grid modeling approach. Energies 2018, 11, 605. [CrossRef]

4. Rusu, E. Numerical Modeling of theWave Energy Propagation in the Iberian Nearshore. Energies 2018, 11, 980. [CrossRef]

5. Stokes, C.; Conley, D. Modelling Offshore Wave farms for Coastal Process Impact Assessment: Waves, Beach Morphology, and Water Users. Energies 2018, 11, 2517. [CrossRef]

6. Son, D.; Yeung, R.W. Optimizing ocean-wave energy extraction of a dual coaxial-cylinder WEC using nonlinear model predictive control. Appl. Energy 2017, 187, 746-757. [CrossRef]

7. Aderinto, T.; Li, H. Ocean Wave Energy Converters: Status and Challenges. Energies 2018, 11, 1250. [CrossRef] 
8. Zhou, Y.; Zhang, C.; Ning, D. Hydrodynamic Investigation of a Concentric Cylindrical OWC Wave Energy Converter. Energies 2018, 11, 985. [CrossRef]

9. Falcao, A.F.O.; Henriques, J.C.C. Oscillating-water-column wave energy converters and air turbines: A review. Renew. Energy 2016, 85, 1391-1424. [CrossRef]

10. Belibassakis, K.; Bonovas, M.; Rusu, E. A Novel Method for EstimatingWave Energy Converter Performance in Variable Bathymetry Regions and Applications. Energies 2018, 11, 2092. [CrossRef]

11. Rajapakse, G.; Jayasinghe, S.; Fleming, A.; Negnevitsky, M. Grid Integration and Power Smoothing of an OscillatingWater Column Wave Energy Converter. Energies 2018, 11, 1871. [CrossRef]

12. Kunwar, A.; Bansal, R.; Krause, O. Steady-state and transient voltage stability analysis of a weak distribution system with a remote doubly fed induction generator-based wind farm. Energy Sci. Eng. 2014, 2, $188-195$. [CrossRef]

13. Barambones, O. Power Output maximization for Wave Power Generation Plants using an Adaptive Sliding Mode Control. In Proceedings of the 2013 International Conference on Renewable Energy Research and Applications (ICRERA), Madrid, Spain, 20-23 October 2013.

14. Rajapakse, A.; Jayasinghe, S.; Fleming, A.; Negnevitsky, M. A Novel DFIG Damping Control for Power System with High Wind Power Penetration. Energies 2016, 9, 521. [CrossRef]

15. Morshed, M.J.; Fekih, A. A new fault ride-through control for DFIG-based wind energy systems. Electr. Power Syst. Res. 2016, 146, 258-269. [CrossRef]

16. Morshed, M.J.; Fekih, A. A Fault-Tolerant Control Paradigm for Microgrid-Connected Wind Energy Systems. IEEE Syst. J. 2018, 12, 360-372. [CrossRef]

17. Pena, R.; Clare, J.C.; Asher, G.M. Doubly fed induction generator using back-to-back PWM converters and its application to variable-speed wind-energy generation. Proc. Electr. Power Appl. 1996, 143, 231-241. [CrossRef]

18. Barambones, O. Sliding Mode Control Strategy for Wind Turbine Power Maximization. Energies 2012, 5, 2310-2330. [CrossRef]

19. Xiong, L.; Li, Y.; Zhu, Y.; Yang, P.; Xu, Z. Coordinated Control Schemes of Super-Capacitor and Kinetic Energy of DFIG for System Frequency Support. Energies 2018, 11, 103. [CrossRef]

20. Taveiros, F.E.V.; Barros, L.S.; Costa, F.B. Back-to-back converter state-feedback control of DFIG (doubly-fed induction generator)-based wind turbines. Energy 2015, 89, 896-906. [CrossRef]

21. Polyakov, A.; Fridman, L. Stability notions and Lyapunov functions for sliding mode control systems. J. Frankl. Inst. 2014, 351, 1831-1865 [CrossRef]

22. Li, P.; Ma, J.; Zheng, Z. Robust adaptive sliding mode control for uncertain nonlinear MIMO system with guaranteed steady state tracking error bounds. J. Frankl. Inst. 2016, 353, 303-321 [CrossRef]

23. Barambones, O.; Alkorta, P.; de Durana, J.M.G. A real-time estimation and control scheme for induction motors based on sliding mode theory. J. Frankl. Inst. 2014, 351, 4251-4270 [CrossRef]

24. Merabet, A. Adaptive Sliding Mode Speed Control for Wind Energy Experimental System. Energies 2018, 11, 2238. [CrossRef]

25. Huang, X.; Zhang, C.; Lu, H.; Li, M. Adaptive reaching law based sliding mode control for electromagnetic formation flight with input saturation. J. Frankl. Inst. 2016, 353, 2398-2417 [CrossRef]

26. Farhat, M.; Barambones, O.; Sbita, L. A new maximum power point method based on a sliding mode approach for solar energy harvesting. Appl. Energy 2017, 185, 1185-1198. [CrossRef]

27. Garrido, I.; Garrido, Aitor J.; Alberdi, M.; Amundarain, M.; Barambones, O. Performance of an ocean energy conversion with DFIG sensorless control. Math. Probl. Eng. 2013, 1-14. [CrossRef]

28. Falcão, A.F.O.; Henriques, J.C.C.; Gato, L.M.C. Rotational speed control and electrical rated power of an oscillating-water-column wave energy converter. Energy 2017, 120, 253-261. [CrossRef]

29. Mishra, S.K.; Purwar, S.; Kishor, N. Maximizing Output Power in Oscillating Water Column Wave Power Plants: An Optimization Based MPPT Algorithm. Technologies 2018, 6, 15. [CrossRef]

30. Alberdi, M.; Amundarain, M.; Maseda, F.J.; Barambones, O. Stalling behavior improvement by appropriately choosing the rotor resistance value in Wave Power Generation Plants. In Proceedings of the 2009 International Conference on Clean Electrical Power 2009, Capri, Italy, 9-11 June 2009; pp. 64-67. 
31. Jayashankar, V.; Udayakumar, K.; Karthikeyan, B.; Manivannan, K.; Venkatraman, N.; Rangaprasad, S. Maximizing Power Output From A Wave Energy Plant. In Proceedings of the 2000 IEEE Power Engineering Society Winter Meeting. Conference Proceedings (Cat. No.00CH37077), Singapore, 23-27 January 2000; Volume 3, pp. 1796-1801.

32. Nagai, B.M.; Ameku, K.; Roy, J.N. Performance of a $3 \mathrm{~kW}$ wind turbine generator with variable pitch control system. Appl. Energy 2009, 86, 1774-1782. [CrossRef]

33. Barambones, O.; De La Sent, M.; Alkorta, P. A Robust Control of Double-feed Induction Generator for Wind Power Generation. In Proceedings of the Annual Conference of the IEEE Industrial Electronics Society, IECON 2009, Porto, Portugal, 3-5 November 2009; pp. 99-104.

34. Utkin, V.I. Sliding mode control design principles and applications to electric drives. IEEE Trans. Ind. Electron. 1993, 40, 26-36. [CrossRef]

35. Gilbert, S. and Patrice, B. SimPowerSystems 5. User's Guide; The MathWorks: Natick, MA, USA, 2005.

(c) 2018 by the authors. Licensee MDPI, Basel, Switzerland. This article is an open access article distributed under the terms and conditions of the Creative Commons Attribution (CC BY) license (http://creativecommons.org/licenses/by/4.0/). 